\title{
China und die Wirtschaft: Der Riese erwacht nicht, er ist längst auf der Überholspur
}

\section{Überblick über das Kapitel}

Die chinesische und die westlich geprägte Welt sind deutlich unterschiedlich. Um die Innovationskraft verstehen und richtig einordnen zu können, die gerade bei KI von China ausgeht und weiter ausgehen wird, zeigt dieses Kapitel, wie sich China im Vergleich zur westlichen Welt wirtschaftlich entwickelt und bis 2050 voraussichtlich entwickeln wird. Dabei wird deutlich, dass China den Westen bereits in einigen Punkten rasant überholt hat und dass dieses Überholen weitergehen wird, insbesondere (aber nicht nur) durch den chinesischen 5-Jahresplan rund um ,Made in China 2025“. Wie es sich u. a. anfühlt, diese Entwicklung hautnah seit 30 Jahren mitzuerleben, berichtet anschließend Beatrix Frisch, General Manager China von Mackevision CG Technologies im Interview. Das Kapitel zeigt anschließend die Unterschiede im Datenschutz sowie dem Datenschutzgefühl (also welche Daten wie schützenswert sein sollten) im Westen und in China. Es diskutiert die damit verbundenen Auswirkungen auf die Implementierungsgeschwindigkeit der chinesischen Gesellschaft in Bezug auf neue, datenverarbeitende Technologien, wie Künstliche Intelligenz eine ist. Es legt dar, dass genau diese Unterschiede im Datenschutz einer der entscheidenden Faktoren dafür sein wird, dass China im Bereich Künstliche Intelligenz die weltweite Führung übernehmen wird.

Anschließend werden die drei wichtigsten 5-Jahrespläne vorgestellt und diskutiert, also: „Made in China 2025“, das die Industrieproduktion Chinas optimieren und mit hochwertigen Erzeugnissen Chinas Position als wichtige Produktionsmacht weiter ausbauen soll; der 5-Jahresplan Chinas von 2017, der die Zeit von 2017 bis 2050 umfasst und der China an die Spitze der führenden Wirtschaftsmächte bringen soll; der Plan des Zentralkommitees zur Rolle der KI von 2017, der KI als den entscheidenden Faktor für China auf dem Weg zur führenden globalen Macht definiert. Das Kapitel zeigt weiter, wie stark China den Bereich KI bereits heute unterstützt. Es liefert Zahlen zu den 
finanziellen Mitteln im eigenen Land, zur globalen Unterstützung von KI-Startups (hier ist China global führend) und bringt Beispiele für die unbürokratische Unterstützung der Behörden, sobald ein Thema im Fokus der chinesischen Planung steht. Außerdem gibt einen breiten Überblick über das Schul- und Universitätsgrogramm Chinas, das so angelegt wird, dass es die nötigen Expert*innen hervorbringt, um zu einer ,AI first“-Nation zu werden. Es folgt ein Interview mit Matthias Müller, dem General Manager des German Center of Industry and Trade in Shanghai, über seine Erfahrungen nach über 20 Jahren in China. Das Kapitel schließt ab mit einem Fazit, warum es sich lohnt, nach China zu schauen.

\subsection{China: „Der Westen“ - im Wirtschaftsmatch}

Typischerweise schauen wir in Europa bei technischen Innovationen in die USA. Und tatsächlich lohnt sich auch bei KI und digitaler Transformation der Blick, über den großen Teich“. Allerdings sind die Entwicklungen auf den Gebieten der KI und der digitalen Transformation in Asien, allen voran China, deutlich schneller und massiver. Aber warum fällt das in Europa und den USA so wenig auf?

Der sogenannte „Westen“ behandelt den sogenannten „Osten“ noch häufig wie die Zeitgenossen von Queen Victoria im 19. Jahrhundert: Die westliche Kultur und Wirtschaft dünken sich noch immer überlegen, China und Indien scheinen vergleichsweise zurückgeblieben und brauchten ggf. sogar Hilfe. Redewendungen wie „developed world“ und „developing world“ sind dafür nur ein erstes, sprachliches Zeichen.

Ab etwa 1850 bis in die 1970er-Jahre mag dieses Bild von China noch richtig gewesen sein:

Der Untergang des kaiserlichen Chinas und damit das westliche Bild war geprägt vom Opiumkrieg und Drogenabhängigen, von günstigen Arbeitskräften aus China für den Bau der US-Eisenbahnen in der zweiten Hälfte des 19. Jahrhunderts, der sogenannten „Hunnenrede“"Wilhelms des II. 1900 angesichts des Boxeraufstandes in China und der Abschottung Chinas nach dem Erstarken des Kommunismus und dem ,großen Sprung vorwärts"von Mao Zedong. Dieser sogenannte große Sprung sollte den zweiten Fünfjahresplan 1958-1962 inhaltlich ausfüllen und die chinesische Wirtschaft auf Augenhöhe mit der westlichen Welt bringen. Tatsächlich musste der Plan gestoppt werden, da die Auswirkungen in eine Hungersnot mündeten, bei der nach vorsichtigen Schätzungen rund 30 Millionen Menschen durch Hunger und Gewalt ums Leben kamen (Gottschalk 2011). So sehr das westliche Bild von diesen rund 120 Jahren geprägt sein mag, so falsch ist es im historischen Vergleich. Denn die 1500 Jahre vor 1850 und die Jahre seit etwa 1980 passen gar nicht in das Bild einer im Vergleich zum Westen unterentwickelten Kultur oder eines zurückgebliebenen Wirtschaftsraumes. Im Gegenteil: China war viele Jahrhunderte räumlich, kulturell und wirtschaftlich eines der führenden, wenn nicht das führende Land auf der Welt. Unter der mongolischen Herrschaft war China ab etwas 1215 das nach Fläche 
größte Land der Erde, ganze vier Mal so groß wie das Römische Reich. Zeitgleich gab es hier die größten Städte der Welt. Man kannte den Buchdruck 500 Jahre vor Guttenberg, und Schießpulver und Papiergeld wurden bereits genutzt (ZDF History Ohne Jahresangabe). Zu Beginn der Ming-Dynastie, direkt nach den Mongolen gibt es um ca. 1430 herum im Reich der Mitte die größte Schiffsflotte der Welt (Dabringhaus 2011)

Etwa seit den 1970er-Jahren erholt sich China wirtschaftlich von der 120 Jahre dauernden Fremdherrschaft und inneren Machtkämpfen, ohne dass dies vom Westen ausreichend registriert wurde. Das, was man ab den 1970er-Jahren von Chinas Wirtschaft hauptsächlich wahrnahm, wirkte zunächst nicht wie die Leistungen einer sich wirtschaftlich entwickelnden Industrienation: Die in den Westen exportierte Billigware "Made in China“ machte China zur „Werkbank“ des Westens und die Qualitätswahrnehmung war gering. Die Studentenaufstände 1989 auf dem Platz des Himmlischen Friedens in Peking und deren blutige Zerschlagung mit den anschließenden, recht halbherzigen, wirtschaftlichen Sanktionen des Westens wirkten im Westen wie ein weiteres Kapitel einer Politik, die keine Demokratie zulassen wollte und wirtschaftlich abhängig vom Westen war. Dieser kurze Abriss macht verständlich, warum der Westen größtenteils zum Gefühl einer gewissen Überlegenheit tendierte, sowohl in moralischer, wirtschaftlicher wie kultureller Hinsicht. „Wie sollte China also jemals in der Lage sein, Vorreiter in Wirtschaft und Kultur zu werden“ hätte man sich fragen können.

Diese Sicht ist heute mehr als überholt. China holt nicht nur auf, es hat den Westen in vielen Bereichen längst überholt und weite Teile der Weltwirtschaft bereits von sich abhängig gemacht. Das gleiche gilt, mit in zeitlicher Verzögerung, für Indien. Ich bin daher genau wie Hans Rosling (2019) der Meinung, dass eine einfache Aufteilung der Welt in „die“ und „wir“ oder „Westen“ und „Osten“, ,developing world“ und „,developed world“ längst nicht mehr ausreicht, um die Komplexität der Welt zu erklären. ${ }^{1}$ Schauen wir uns das näher für China an:

Zum einen zeigt China ein enormes wirtschaftliches Wachstum. Zwischen 1980 und 2017 wuchs das Bruttoinlandsprodukt pro Kopf, kaufkraftbereinigt, um den Faktor 34, während das BIP Deutschlands und der USA nur um den Faktor 4 bzw. 5 zulegten, zugegeben von einem sehr hohen Niveau kommend. Das BIP Indiens, dem bevölkerungsreichsten Land nach China, wuchs im selben Zeitraum um den Faktor 13 (siehe Abb. 2.1). Gleichzeitig sank die Zahl der Menschen in extremer Armut - das sind Menschen, die bis 1 US-Dollar am Tag zur Verfügung haben: Lebten in Indien und China 1997 noch $42 \%$ der Bevölkerung in extremer Armut, ist dieser Wert 2017 in beiden Ländern gesunken: In Indien fiel er auf absolut $12 \%$, das sind 270 Millionen Menschen weniger Menschen, die in Armut leben. In China reduzierte sich der Wert sogar auf 0,7 \% absolut - das sind rund eine halbe Milliarde Menschen, die nicht mehr in absoluter Armut leben müssen (Rosling 2019, S. 69). Von Chinas positiver wirtschaftlicher Entwicklung profitieren vielleicht nicht alle Chinesen gleichermaßen, aber sie verbessert substantiell das Leben fast aller Chinesen.

\footnotetext{
${ }^{1}$ Ein ganz wunderbares Buch, das aufräumt mit ,wir“ und „,die“ ist „Factfullness“ von Hans Rosling sowie dessen NGO ,gap minder“ (https://www.gapminder.org).
} 


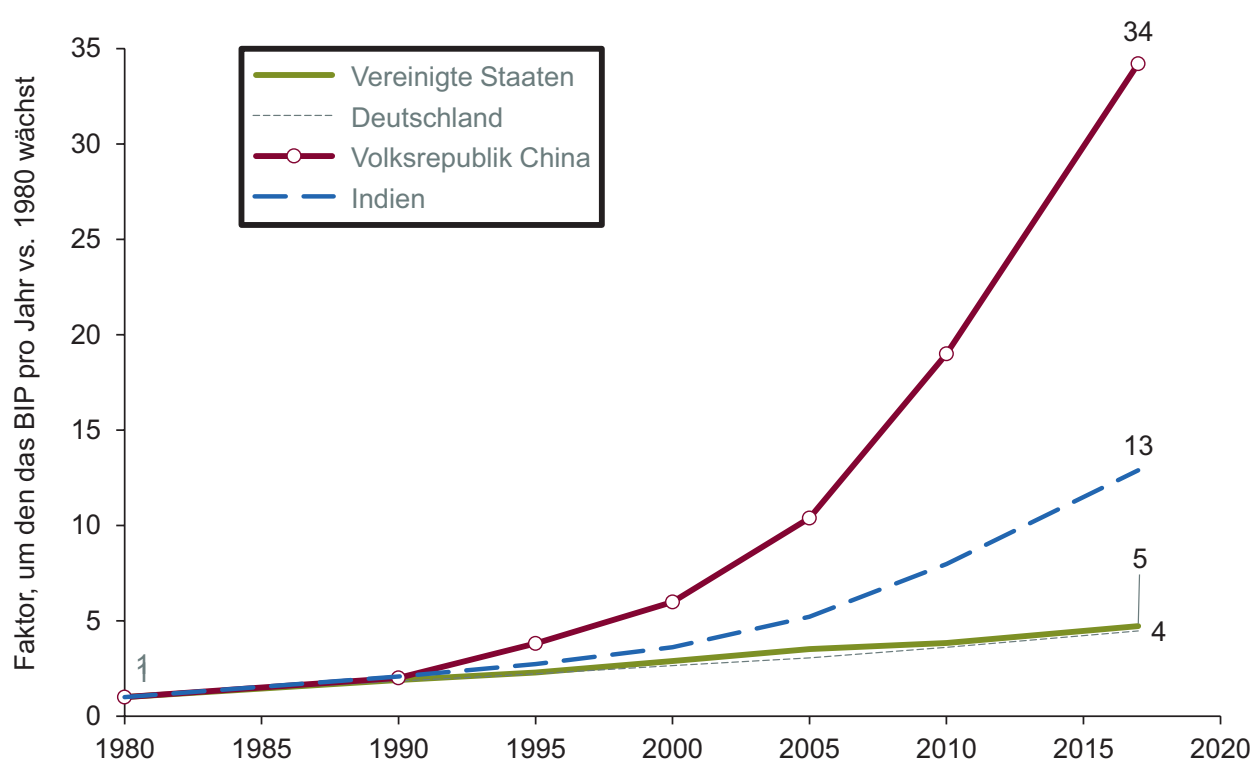

Abb. 2.1 Steigerung Bruttoinlandsprodukt pro Kopf kaufkraftbereinigt. (Eigene Darstellung nach (International Monetary Fund 2018))

Diese Entwicklung wird sich auch in Zukunft fortsetzen. Abb. 2.2 zeigt, dass pwc von 2016 bis 2050 ein Wachstum des Bruttoinlandsprodukts um $175 \%$ für China und um $407 \%$ für Indien prognostiziert. USA und Deutschland bleiben nach diesen Berechnungen mit $83 \%$ bzw. $53 \%$ Wachstum des BIP relativ abgeschlagen zurück (pwc 2017). Nun könnte man argumentieren, dass China viel größer und von einem extrem niedrigen Niveau gestartet ist, so dass Vergleiche der Steigerungsraten unfair sind. Schauen wir uns daher „,noch“ fairere Daten an: Die Gapminder Foundation zeigt das Einkommen eines Landes pro Kopf, kaufkraft- und inflationsbereinigt, von 1800 bis 2040, siehe Abb. 2.3. Die zugrundeliegenden Daten kommen ebenfalls vom IWF. Es ist unschwer zu sehen, dass selbst bei diesem sehr fairen Vergleich der Daten zwei Dinge auffällig sind: Erstens: Die USA und Deutschland sind sehr stetig gewachsen, außer in den Jahren während der beiden Weltkriege. China und Indien dagegen blieben bis ca. 1980 abgeschlagen. Zweitens: Seit ca. 1980 holen beide auf (Gapminder 2019). In einem TED Talk errechnet Hans Rosling, Gründungsmitglied von Gapminder, den Zeitpunkt, zu dem China, bei vergleichbaren Einkommen seiner Bürger*innen, zu den USA aufgeschlossen hat, für das Jahr 2048. Bis dahin sind es noch gut 28 Jahre und es ist ein Jahr vor dem 100. Geburtstag der Volksrepublik China. Wenn nichts dazwischenkommt, und es kommt häufig etwas bei Trendanalysen dazwischen, ist China auf einem sehr guten Weg, dies zu schaffen.

Bereits heute gehört China zu den industriellen Maschinenräumen der Welt. Der Industriesektor trägt mehr als 40 Prozent zum Wirtschaftswachstum bei, zugleich sind 90 Prozent aller exportierten Güter Industrieprodukte. Autos kommen weltweit zu $28 \%$ aus China, 


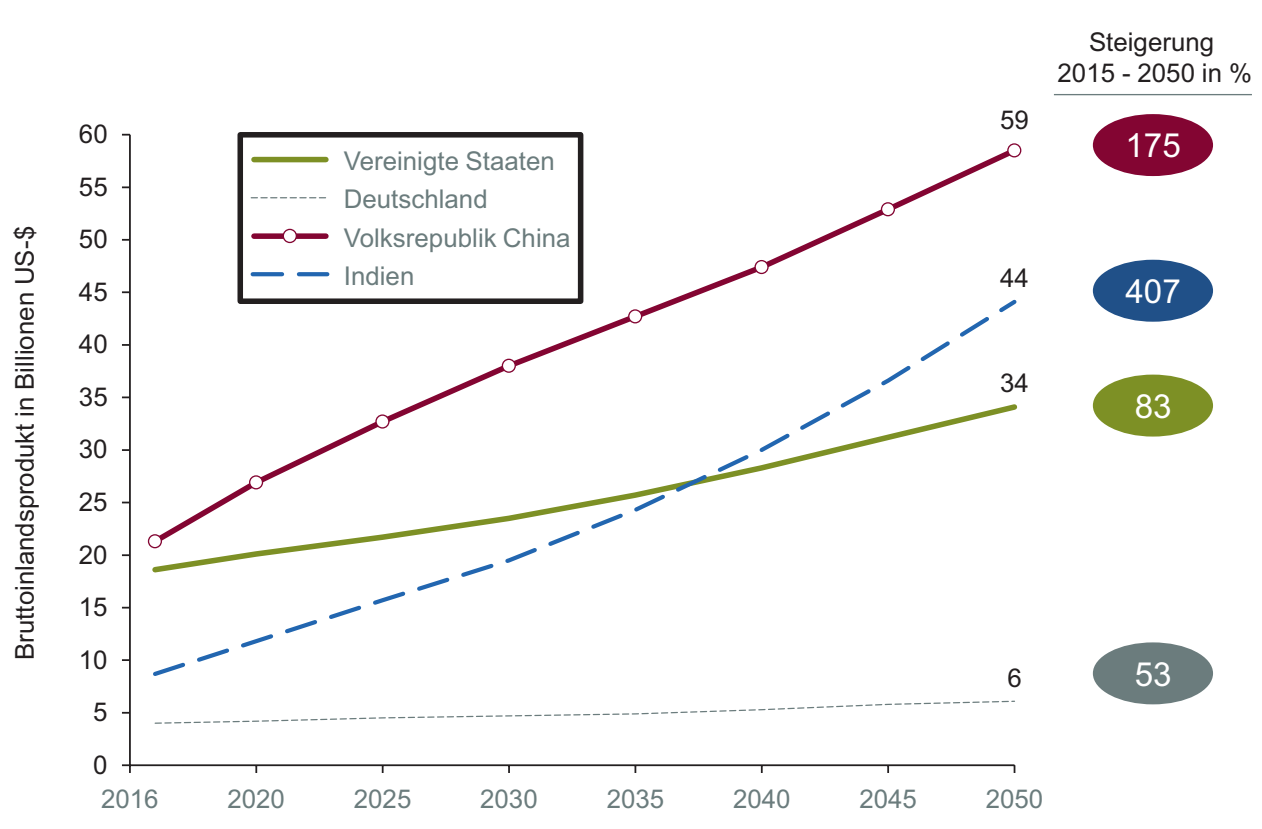

Bruttoinlandsprodukt währungsbereinigt/kaufkraftparitätisch

Abb. 2.2 Schätzung Steigerung Bruttoinlandsprodukt 2016 - 2050. Eigene Darstellung nach (pwc 2017)

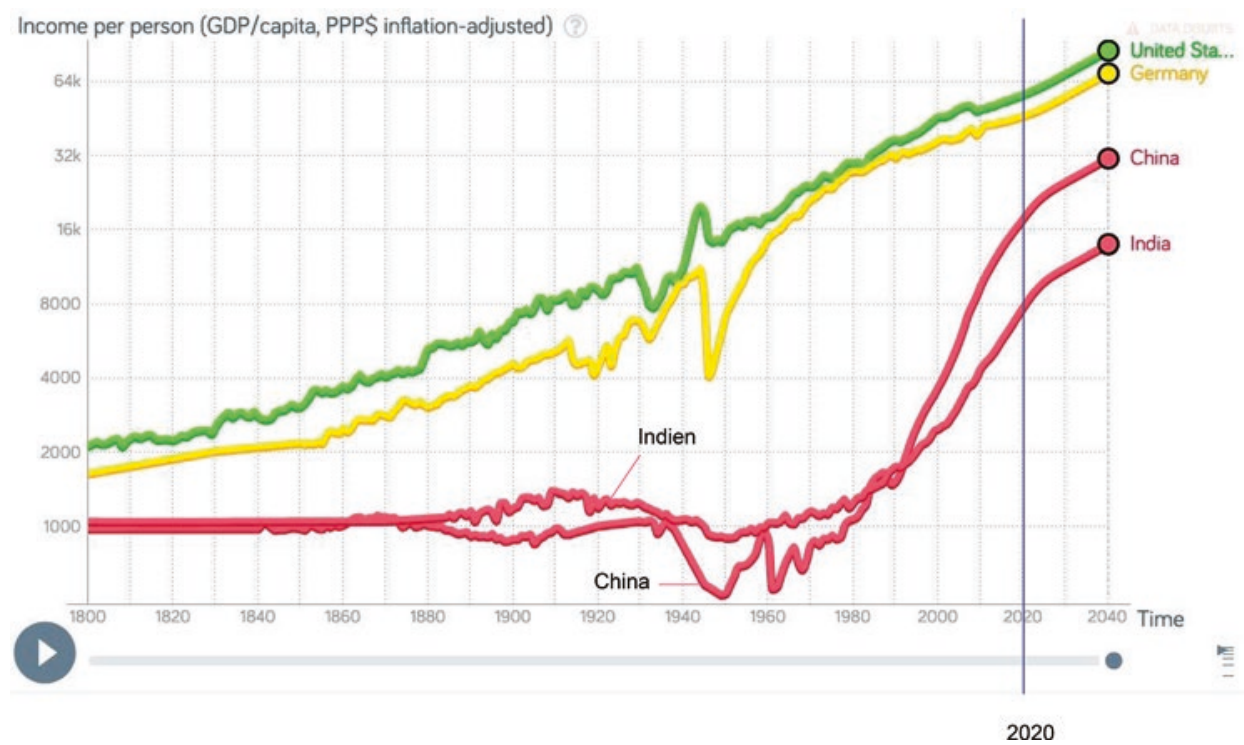

Abb. 2.3 Pro Kopf Einkommen 1800 - 2040 (Gapminder 2019) 
Schiffe zu $41 \%$. Bei Zukunftsgütern wie Computern und Handys werden zwischen 80 und 90 Prozent der weltweiten Produktion in China gefertigt. Und der Coronavirus zeigt diese Abhängigkeit im Frühjahr 2020 sehr deutlich: Apple spricht im Februar eine Gewinnwarnung aus, es mangele an Iphones weltweit, und Deutschlands Medikamentenversorgung hängt am Tropf von China. Doch nach wie vor wird in China vor allem mit der Hand gearbeitet. Die Automatisierungsquote in der Produktion liegt weit unter den Werten von europäischen Industrieländern oder auch Chinas ostasiatischen Konkurrenten wie zum Beispiel Südkorea. Während China nur über 49 Roboter auf 10.000 Arbeiter verfügt, nennt der Durchschnitt der Welt 69 Roboter auf 10.000 Arbeiter ihr Eigen, ausgenommen Spitzenreiter wie Südkorea (531 Roboter) und Deutschland (301 Roboter), die die Durchschnittswerte weit übertreffen (Benrath et al. 2018). Das soll der Plan „Made in China 2025“ grundlegend ändern, den ich in diesem Buch ebenfalls vorstellen und diskutieren werden. Dieser Plan ist aber nur ein kleines Teilstück des von Xi Jingping, dem chinesischen Staatspräsidenten, angestrebten Projekts. Seit 2012 führt er das Land und ist seit 2018 durch keine Amtszeitbegrenzung mehr eingeschränkt. Seine politische Vision umfasst die Zeit bis 2049, wenn Chinas kommunistische Partei 100 Jahre alt wird. Bis dahin will Xi China zur führenden Wirtschafts- und Militärmacht entwickeln und nennt das den „Chinesischen Traum“.

Zum diesem „Chinesischen Traum“ gehört auch der Ausbau der sogenannten „Neue Seidenstraße“, das größte Infrastrukturprojekt Chinas außerhalb der eigenen Grenzen. Der Plan sieht vor, einen Seeweg und einen Landweg von China bis nach Europa zu schaffen. China will angeblich 900 Milliarden US-Dollar in dieses Vorhaben investieren (Steinmetz 2017) und bietet den betroffenen Ländern großzügige Kredite an, wenn sie sich daran beteiligen. 60 Länder haben von diesem Angebot bereits Gebrauch gemacht. China hat parallel dazu den Hafen von Piräus in Griechenland gekauft und hält $10 \%$ der Anteile des Flughafens von Toulouse in Frankreich (Lepault und Franklin 2018). In Dschibuti, einer kleinen Republik an der Ostküste von Afrika, hat China 2017 die erste Militärbasis außerhalb Chinas eröffnet. Dschibuti liegt strategisch günstig am Eingang zum Roten Meer, einem Teil der seeseitigen Seidenstraße (Steinmetz 2017).

China engagiert sich ebenfalls in Afrika und vergibt dort Kredite für Infrastrukturprojekte (Lepault und Franklin 2018), kauft global Wasservorräte und Land auf und war bereits 2012 nach der US-Notenbank der größte Gläubiger der USA (Hackhausen 2012). Mit mehr als einer Billion US-Dollar in 2017 liegt die Verschuldung der USA bei China in 2018 schon bei 1,2 Billionen US-Dollar (Manager Magazin 2018).

Uns mag nicht alles gefallen, was wir sehen, angefangen von fehlender Mitbestimmung der Bürger*innen am politischen Geschehen über den aus westlicher Sicht mangelnden Datenschutz bis hin zu einem unguten Gefühl in westlichen Wirtschaftskreisen, die eigenen Innovationen, einmal in China auf den Markt gebracht, würden nicht mehr so geschützt, wie man es von einem europäischen Patentschutz erwarten könnte. Aber nur, weil es uns nicht gefallen mag, heißt dies nicht, dass es nicht stattfinde oder uns nicht betreffe.

Es gibt Stimmen, die meinen, dass sich China, um wirtschaftlich weiter erfolgreich zu sein, in Zukunft mehr um seine Bürger*innen kümmern müsse. Dyer, ein Journalist der Financial Times und vormaliger Büroleiter der Financial Times in Peking, schrieb dazu im Jahr 2014: 
„On the economic side, the growth model that relies on funneling cheap bank loans to investment projects is running out of steam and needs to be replaced by more emphasis on consumers. Most of the goals that China has set itself for the coming decades, weather it is encouraging more innovation or winning cultural recognition, are rooted in the initiative of private citizens. The next Chinese era will be less about the state and much more about the individual. XI's challenge is to chart a series of reforms that start to address these demands without provoking a backlash from the party's many and powerful vested interests“ (Dyer 2014, S. 277).

Sollte dies umgesetzt werden - und es sieht ganz danach aus - wird es dem einzelnen Chinesen und der einzelnen Chinesin wirtschaftlich immer besser gehen und der individuelle Konsum wird weiter zunehmen. E-Commerce, B2C-Marketing und KI als unterstützendes Tool kommen in diesem Spiel eine Schlüsselrolle zu, die ich im Folgenden noch eingehender erörtern werden.

Chinas wachsende Bedeutung in der Wirtschaft wird uns in der sogenannten ,entwickelten“ Welt umdenken lassen müssen. In nur wenigen Jahren wird ein normaler Börsenbericht in Deutschland starten mit dem DAX, gefolgt vielleicht vom SSE Composit Index für China und womöglich erst danach dem Dow Jones Index der USA. Einige Zeit später wird der BSE Sensex eventuell noch vor dem Dow Jones kommen. Was das ist? Der Aktienleitindex für Indien; Indien, nach Einwohnerzahl 2018 noch rund 4 \% hinter China (International Monetary Fund 2019), wird im Jahr 2050 das bevölkerungsreichste Land der Erde mit dann geschätzten 1,6 Milliarden Einwohnern sein und damit eine Bevölkerungszahl aufweisen, die rund $25 \%$ höher ist als die Chinas (UN 2019).

\subsection{Einschätzungen von Beatrix Frisch von Mackevision CG Technologies: „Die Annahme von Innovationen ist in China generell positiver"}

Beatrix Frisch ist in Personalunion Regional Director APAC und General Manager China von Mackevision CG Technologies, einem der weltweit führenden Provider für 3D Visualisierungen. Zudem ist Mackevision seit Anfang 2018 Teil von Accenture Interactive. Frau Frisch lebt und arbeitet seit über 30 Jahren in China und hat die rasanten Veränderungen im täglichen Leben, der Wirtschaft und im Marketing live miterlebt. Nach dem Studium der Sinologie und Abschluss in Marketing Ostasien, arbeitete sie bei diversen Unternehmen der Automobilbranche im China-Geschäft, für den Sportartikelhersteller adidas, und anschließend fünf Jahre als freiberufliche Beraterin für diverse Unternehmen. Seit 2015 ist Mackevision ihr Arbeitgeber, deren Standort in China sie maßgeblich aufbaute. Hier berichtet sie von ihren Chinaerfahrungen.

Was ist für Sie der größte Unterschied zwischen China und der westlichen Welt, wenn es um Innovationen und Marketing geht?

Einerseits ist die Annahme von Innovation generell positiver und willkommener denn in der westlichen bzw. entwickelten Welt (Japan gehört hinzu, liegt aber im Osten). Jedoch 
ist dies auch ein natürliches Phänomen, wenn man bedenkt, dass jahrhundertelanges Abschotten sowie die Kulturrevolution mit den folgenden Jahren des Chaos keine Modernisierung ermöglichten. Mit Deng Xiaopings Vorstoß, den Fortschritt proaktiv ins Land zu lassen, wurde das Innovationsklima zunächst nur langsam genährt. Vorwiegend kamen veraltete Technologien und Produkte ins Land, was sicherlich auch mit dem zunächst vergleichsweise geringerem Einkommens- und Entwicklungsniveaus in China zu tun hatte. Schnell jedoch kam die Lust am Neuen, auch mit wachsender Möglichkeit, ins Ausland zu reisen und zu guter Letzt natürlich auch mit der rasanten Verbreitung des Internets, das weitere Impulse setzte. Daraus entwickelte sich jedoch ein Hunger nach dem nächsten neuen Trend, der zu einer relativ schnellen Müdigkeit mit Blick auf das gerade Erreichte führte. Insofern gab es oft wenig Chancen, das, was gerade neu und in war, vernünftig und nachhaltig weiter zu entwickeln.

Im Gegensatz hierzu hat sich das Marketing nicht so schnell und auch nicht in der gleichen Art entwickelt, wie in der ,westlichen“ Welt. Der Unterschied liegt darin, dass Chinesinnen und Chinesen ein vermehrtes Maß an Informationen zu einem Produkt haben wollen. Dies liegt zum einen am gewissen Mangel an einer durchgängigen Erfahrung mit den Produkten oder Serviceangeboten, zum anderen durchaus auch an der anderen Sprachkultur, die eher visuell orientiert ist (chinesische Schriftzeichen sind keine Buchstaben, sondern stammen von Piktogrammen). Das Marketing in China muss also sehr visuell und erläuternd sein. Experience Marketing hat in China daher einen weitaus höheren Stellenwert als im Westen.

Ein weiteres Phänomen ist die rasante Entwicklung des Online-Handels und die Rolle des digitalen Marketings. Dies ist vor allem der Größe des Landes geschuldet, die eine durchgängige und gleichmäßige Durchdringung mit Gütern und Services erschwert. Zudem ist durchaus eine Differenzierung von Bildungsständen und Einkommen zu bedenken, die sich wiederum in zeitlich versetzten Adaptionen von Innovationen zeigt (Tier 1-Städte bzw. Megalopolen gegenüber Tier 4 und 5)

Marketing wurde in der Anfangszeit vor allem durch die ausländischen Firmen geprägt; die chinesischen Marken entwickelten ihr Marketingverständnis zuerst nachahmend aus, denn was die Ausländer ausführten, galt als Vorbild und „state of the art“. Eine kopierte Marketingbotschaft konnte fast schon eher als Hommage oder Kompliment für die originale Marke gesehen werden. In der Zwischenzeit und mit wachsendem Nationalstolz entwickelte sich dann eine China-eigene Marketingwelt, in der die Notwendigkeit für Markenstrategie und konsistente Marketingplanung zunächst erst langsam erkannt und angegangen wurde.

Was würden Sie sagen: Ist China bei KI im Marketing vor oder hinter Europa? Wie viele Jahre?

Im Prinzip ist meiner Einschätzung nach China definitiv vor Europa anzusiedeln, alleine basierend auf dem fast unbegrenzten Zugang zu einem der größten Datenpools der Welt. In China kennt man keine gesetzliche Restriktion à la DSGVO, es ist maximal der Export personenbezogener Daten ins Ausland geschützt und ab einem Umfang von 50.000 persönlichen Datensätzen gesetzlich verboten. Mit der Vorgabe von Echtnamen- 
Registrierungen für Telefon und Internetkonten vor einigen Jahren wurde dieser Zugang zu Echtdaten möglich und einfach. Alleine aufgrund der Bevölkerungsgröße und der massiven Durchsetzung der Nutzung von mobilen Diensten und Anwendungen im Alltag kann man von einem guten Entwicklungsstand ausgehen. Zumal auch die Bevölkerung hier keine Aversionen zeigt, einfach gesagt, weil sie nichts anderes kennt.

Wieweit allerdings die tatsächliche Nutzung und Anwendung der Daten im Bereich KI vorangeschritten ist, ist für mich schwer einzuschätzen, da ich hier keine direkten Erfahrungen besitze. Jedoch ist davon auszugehen, dass die meisten chinesischen Unternehmen einfacher auf die Anwendung von KI eingehen können, da sie weniger etablierte Strukturen vorweisen. Auch die Belegschaft ist im Schnitt jünger und eher der digitalen Generation zuzuordnen, was die Einbindung von KI vereinfacht und somit die allgemeine Entwicklung in und mit dieser Ressource vorantreiben kann und wird.

Was wäre aus Ihrer Sicht die größte Veränderung, die Marketing- und Salesmanager*innen in Europa in den nächsten 5 Jahren erfahren werden?

Der Bedarf und die Anwendungsmöglichkeiten für Programmatic Marketing, von Diensten zur Individualisierung und die Integration zwischen verschiedenen Industrien werden sich rasant weiterentwickeln. In unserem eigenen Bereich der 3D-Visualisierung mit Computer-generierten Bildern (CGI) erleben wir einen der schnellsten Wandel der letzten fünf Jahre. Bedarf und Verfügbarkeit an Ressourcen (KI, Mensch und Maschine) treiben die Entwicklung fast schon in Wochenschritten voran.

Sie erleben seit 30 Jahren die positive wirtschaftliche Entwicklung in China mit. Hätten Sie ein paar Beispiele aus Ihrem Alltag, die diese Entwicklung zeigen?

Die Mobilität ändert sich: Vor drei bis vier Jahren konnte man noch ein Taxi an der Straße heranwinken. Mittlerweile geht dies nur noch mit einer der gängigen (und mehr werdenden) Mobilitäts-Apps wie DIDI.

Bezahlen mit Bargeld wird als veraltet angesehen, man nutzt hier nur noch das Mobiltelefon mit WeChat Pay oder AliPay - das gilt auch für den Straßenverkäufer.

Flugzeuge sind vorwiegend mit chinesischen Passagieren gebucht, Ausländer sieht man nur noch selten. Und: Chinesische Kollegen nehmen mittlerweile tatsächlich ihren Urlaub, um die Welt zu erkunden.

Das Prozedere für Visa (Reise-oder Arbeitsvisa) ist für Ausländer komplexer und schwieriger geworden - China scheint die Einreise von Ausländern generell beschränken $\mathrm{zu}$ wollen, und für Arbeitsvisa gerade wegen einer wachsenden eigenen Arbeitsbevölkerung.

Das Stadtbild ändert sich: Die alten Gebäude weichen modernen mit wenig chinesischen Merkmalen. Einerseits ist es nachvollziehbar, dass alte (marode) Gebäude verschwinden; doch gleichzeitig verlieren die Städte auch an kultureller Identität.

Doch bei allem Fortschritt bleiben einige Phänomene auch unverändert: Bankgeschäfte zum Beispiel bedürfen einer Vorort-Präsenz mit einem Zeitaufwand von mindestens einer Stunde (ausgenommen ist der Transfer zwischen Konten bis zu einer gewissen Summe innerhalb Chinas).

Woran liegt diese positive Entwicklung aus Ihrer Sicht? Was macht China richtig? 
Das hat nichts mit richtig oder falsch zu tun, sondern hat zum einen mit dem enormen Bedarf, der nach den langen Jahren der Abschottung erkannt wurde. Zum anderen ist es natürlich die Tatsache, dass China ein Ein-Parteien-Staat ist, der in sozialistischer Manier eine Planungsökonomie betreibt und somit alle Entscheidungen in zentraler Art trifft, mit Roll-out in die Provinzen. Sämtliche Infrastruktur ist staatlich, Innovationsprojekte werden staatlich geplant und gelenkt. Das Einzelschicksal hat sich einerseits dem unterzuordnen, auch ggf. die Natur. Für die Hochgeschwindigkeitsstrecken werden z. B. gerade Strecken geplant, so weit möglich; liegt ein Dorf, Feld oder Wald im Weg, so gibt es keine Umweltschützer, die sich in den Weg stellen. Andererseits ist die chinesische Bevölkerung stolz auf die Entwicklung und unterstützt sie, auch wenn es einmal gegen den eigenen Willen und das eigene Wohl geht.

Marketing lebt ja viel von Daten und Datenverknüpfung. Was unterscheidet den Datenschutz in China von dem in Europa?

Seine Nichtexistenz und die Unterordnung unter das Allgemeinwohl. Es erscheint mir außerdem oft so, dass in China das berühmte ,bigger picture“ nicht gesehen wird oder in zu engen Grenzen, den chinesischen Grenzen. Die Tatsache, dass andere Länder und Kulturen anders funktionieren, scheint auch den chinesischen Marketern fremd oder schwierig zu sein.

Wenn Sie Marketingmanager*innen und Werber*innen in Europa einen Tipp geben sollten, was sie mehr/besser machen sollten, um wettbewerbsfähig zu sein, was wäre das?

Sich informiert halten, was in den diversen Regionen der Welt geschieht. Anzunehmen, dass überall deutsche, westliche oder amerikanische Verhältnisse bestehen, ist genauso falsch, wie anzunehmen, dass das deutsche Marketing für amerikanische Konsument*innen passt. Die kulturellen und sprachlichen Belange und Bilder sind divers und diffizil.

Im Ausland zu arbeiten, vor allem in einem Land, das weniger bekannt oder entwickelt ist, erweitert den Horizont.

Zudem sollte man danach streben, relevant zu bleiben, zu wissen: „Was sind Trends, technologische Bedingungen und Bedarfe, ohne die sich die Welt in der nahen Zukunft nicht mehr bewegen wird?

\subsection{China: „Der Westen“ - im Datenschutzvergleich}

Fragte man Politiker*innen aus Europa und China, ob Datenschutz wichtig sei, stimmten vermutlich alle zu. Aber europäische Politiker*innen meinen mit dem Schutz von Daten eher Individualdaten, also den Schutz der persönlichen Daten vor Missbrauch, z. B. gegenüber Unternehmen oder dem Staat. Erst an zweiter Stelle kommt der Landesschutz bei der Datensicherheit. Für chinesische Politiker*innen ist es genau umgekehrt. Es gilt in erster Linie, die Gemeinschaftsdaten aller Chinesen vor anderen Ländern zu schützen und dafür zu sorgen, dass die Sicherheit der Gesellschaft gewahrt bleibt. Ein individueller Schutz der Persönlichkeitsdaten vor dem eigenen Staat steht dabei weniger im Fokus. 
China schützt sich gegen Datenverlust und Datenklau vor allen Dingen als Land, während in Europa mit dem neuen DSGVO mehr die Individualrechte der Bürger auf Schutz ihrer Daten gesichert werden. Wie wir sehen werden, erlaubt diese gegensätzliche Priorisierung innerhalb des Datenschutzes in China chinesischen Firmen mehr als denjenigen aus Europa und den USA, Daten zu verknüpfen und zu verarbeiten. Denn chinesische Firmen sammeln und speichern eine größere Menge an Daten und dürfen diese nach chinesischem Recht stärker verknüpfen als es westlichen Firmen erlaubt ist. Kombiniert mit Künstlicher Intelligenz bei der Verarbeitung dieser Daten wird für China daraus ein entscheidender Wettbewerbsvorteil.

Gesche Joost, Designforscherin an der Universität der Künste Berlin, die zur Zeit ein Forschungsjahr in Peking absolviert, fasst es sinngemäß so zusammen: In China werde Sicherheit und individueller Datenschutz anders gegeneinander abgewogen als in Europa. In China sei wichtiger, dass durch eine größere Überwachung und damit auch durch das Aufgeben eines individuellen Datenschutzes die Sicherheit der Bevölkerung insgesamt steige. So sei beispielsweise die Kriminalitätsrate gesunken, seit mit KI Personalüberwachung möglich sei. China habe eine andere Tradition, was die Abwägung des individuellen Sicherheitsbedürfnisses gegen das der Gesellschaft angeht. (Wolff und Yogeshwar 2019).

\section{Die chinesischen Datenschutzgesetze}

Erst 2014 hatte Chinas Staats- und Parteichef Xi Jinping die Cybersicherheit zu einer Frage der nationalen Sicherheit erklärt (Alsabah 2017). Seitdem gibt es in China viel Bewegung im Datenschutz, eine regelrechte Aufrüstung. Das ist insbesondere vor dem Hintergrund der rasant wachsenden Nutzung von Onlinediensten wichtig und nötig. 731 Millionen Internetnutzer gab es in 2016 in China (Alsabah 2017) und es musste festgelegt werden, wer wann wie diese Daten verarbeiten und nutzen darf. Das Cybersicherheitsgesetz vom 1. Juni 2017 regelt einen Teil davon. Es soll für Datensicherheit, den Schutz kritischer Infrastrukturen sowie zu einem kleineren Teil für den Schutz der Privatsphäre chinesischer Bürger sorgen. Auf diese Weise zwingt es auch ausländische Unternehmen zu einem hohen Grad an Transparenz. Bei Nichteinhaltung drohen empfindliche Strafen bis zum Entzug der Gewerbeerlaubnis. Nach Alsabah ergeben sich daraus für westliche Firmen vier Herausforderungen (Alsabah 2017):

Erstens müssten laut dem Cybersicherheitsgesetz von 2017 IT-Produkte, die zu den sogenannten „Kritischen Infrastrukturen“ zählen, eine staatliche Sicherheitsprüfung bestehen. Das neue Gesetz klassifiziere folgende Infrastrukturbereiche als kritisch: Kommunikationswesen, Energie, Transport, Wasserversorgung, Finanzwesen sowie E-Government-Dienstleistungen. Darüber hinaus werde nicht genauer definierte Bereiche genannt, die Auswirkungen auf die „,nationale Sicherheit“, „,das Wohlergehen der Bürger“ oder das „öffentliche Interesse“ haben. Diese vagen Formulierungen erlaubten es den Behörden, weitere Bereiche als „kritisch“ einzustufen. Die Sicherheitsanforderungen würden für alle Produkte gelten, die mit digitalen Daten zu tun haben. Ausländische Technologien betrachtet man besonders kritisch. 
Zweitens seien Unternehmen verpflichtet, bestimmte Daten in Zukunft lokal zu speichern. (Nutzer-)Daten, die von Betreibern „Kritischer Infrastrukturen“ gesammelt werden, müssen nach dem Cybersicherheitsgesetz innerhalb Chinas gespeichert werden.

Drittens zwingt das Antiterrorismusgesetz von 2015 Unternehmen, staatlichen Behörden Zugriff auf die Daten von Terrorverdächtigen zu gestatten. Das könne sich als äußerst problematisch erweisen, etwa für Unternehmen, welche die sogenannte Ende-zu-EndeVerschlüsselung einsetzen. Sie verfügten damit nicht über die technischen Möglichkeiten, die Daten ihrer Konsument*innen einzusehen und könnten einer entsprechenden Aufforderung daher nicht nachkommen. Das Gesetz lasse hier keine Ausnahmen zu.

Viertens schreibe die ,Verordnung über den kommerziellen Einsatz von Verschlüsselung“ (1999) vor, dass Unternehmen ihre Daten nur mit staatlich genehmigten Technologien verschlüsseln dürften. Der Import von Sicherheitsroutern, Firewalls und Verschlüsselungssoftware müsse vom Office of State Commercial Cryptography Administration (OSCCA) genehmigt werden. Diese Regelung schränkte den Import und Verkauf von ausländischen Verschlüsselungsprodukten in China stark ein.

Die Individualdatenschutzrechte der chinesischen Bürger sind im Cybersicherheitsgesetz indirekt dadurch geschützt, dass in China generierte Daten chinesischer Bürger nach diesem Gesetz auch in China bleiben sollen. Generell gilt, dass Daten aus China nicht weitergegeben werden dürfen, wenn:

- Es sich um personenbezogene Daten handelt, für die keine Einwilligung vorliegt oder die den persönlichen Interessen der betroffenen Person entgegenstehen,

- Daten, die kritische Infrastrukturen betreffen, dem öffentlichen Interesse entgegenstehen oder der nationalen Sicherheit schaden können und

- anderweitig von öffentlichen Sicherheitsstellen vom Transfer ausgeschlossene Daten.

Den Nutzern muss vor dem Datentransfer mitgeteilt werden, um welche Daten es sich handelt, wie umfangreich diese Daten sind, was der Zweck der Übertragung ist und wer diese Daten erhält. Die Nutzer müssen dieser Erklärung zustimmen. Handelt es sich um Minderjährige, muss die Einverständniserklärung der Erziehungsberechtigten eingeholt werden (W4, Ohne Jahresangabe).

Es ist ersichtlich, dass es weniger um den Schutz individueller, persönlicher Daten geht, sondern vielmehr darum, dass chinesische Daten in China bleiben. Es ist also ein als Persönlichkeitsrecht ,,verpackter“ Landesdatenschutz.

Individualrechte gegenüber dem chinesischen Staat sind dagegen weniger geschützt. Hier gibt es zahlreiche Vorgaben, viele Behörden, die Daten sammeln und massenhaft Löcher bei der Datenspeichersicherheit:

Bis dato gibt es in der Volksrepublik kein einheitliches nationales Gesetz zum Schutz von personenbezogenen Daten. Ein 2003 vom Staatsrat in Auftrag gegebener Entwurf liegt auf Eis. Im März 2017 wollten einige Delegierte des Nationalen Volkskongresses das Thema wieder auf die Tagesordnung setzen, stießen aber kaum auf Gehör. Das werde noch mindestens drei oder fünf Jahre dauern, sagte einer der Delegierten, Yang Zhen, den Me- 
dien (Shi-Kupfer und Chen, Massenhaft Nutzer - mangelhafter Datenschutz, 2017, S. 2). Es gibt offenbar ein sich oft überlappendes Nebeneinander von branchenspezifischen Regulierungen, nach Shi-Kupfer und Chen, zum Schaden der Nutzer: Sie müssten jedem Datentransfer, sei es für die Onlinebezahlung eines Wohnungskaufs, einen Krankenhausbesuch oder für die Registrierung an der Universität neu zustimmen. Ihre Daten lägen mit unterschiedlichen Standards kodiert und unterschiedlich gut geschützt gleich bei mehreren Behörden. (Shi-Kupfer und Chen, Massenhaft Nutzer - mangelhafter Datenschutz, 2017, S. 1).

Immer wieder kommt es offenbar zu Datenschutzlücken bei den von Behörden gesicherten Personendaten: So verlor eine Studentin aus der östlichen Provinz Shandong ihr gesamtes, für das Studium vorgesehene Geld, an eine Hackerbande. Als Köder dienten den Kriminellen die persönlichen Daten der Studentin, die sie sich - mit 600.000 weiteren Datensätzen - aus der offensichtlich nicht gut geschützten Datenbank des lokalen Bildungsbüros gezogen hatten. Im Zweifelfall werden die Firmen oder die Nutzer zur Verantwortung gezogen, nicht aber staatliche Stellen (Shi-Kupfer und Chen, Massenhaft Nutzer - mangelhafter Datenschutz, 2017, S. 2).

Chinesen wertschätzen ihre Individualrechte aber offenbar auch weniger als Bürger der westlichen Welt. Nach einer Umfrage der Boston Consulting Group aus dem Jahr 2014 fand nur die Hälfte aller befragten Nutzer in China, dass man beim Teilen von persönlichen Daten vorsichtig sein müsse, 26 Prozentpunkte weniger als der Durchschnitt der Befragten aus weiteren zehn Ländern. 63 Prozent stimmten zu, dass ihre Kreditkarteninformationen ,relativ bis sehr privat“" seien. In den USA waren es 87 Prozent, in Deutschland 93 Prozent. (Shi-Kupfer und Chen, Massenhaft Nutzer - mangelhafter Datenschutz, 2017, S. 1). Das mag auch daran liegen, dass für viele chinesische Nutzer die Bequemlichkeit über der Frage des Datenschutzes steht: 96 \% gehen, laut Studie, mit Smartphone online, und damit von unterwegs aus (Dorloff 2019). Vor einem Kauf die AGBs gründlich durchlesen oder mühevoll Formulare ausfüllen, will offenbar kaum jemand. Auch bei Lee finden sich entsprechende Kommentare: „But people in China are more accepting of having their faces, voices, and shopping choices captured and digitized. This is another example of the broader Chinese willingness to trade some degree of privacy for convenience." (Lee 2018, S. 124).

China erarbeitet weitere Vorlagen zum Schutz von Daten, insbesondere personenbezogenen Daten: Ende 2016 legte Chinas nationales Komitee für die Standardisierung von Informationssicherheitstechnik einen Entwurf zur nationalen Vereinheitlichung der rechtlichen Standards für den Schutz personenbezogener Daten vor. Im Mai 2017 entwarf das Komitee ein weiteres Dokument zum Schutz personenbezogener Daten bei grenzüberschreitenden Transaktionen, das vor allem den Onlinehandel betrifft (Shi-Kupfer und Chen, Massenhaft Nutzer - mangelhafter Datenschutz, 2017, S. 2). Das Gesetz, das seit 1. Januar 2019 in Kraft ist, regelt den E-Commerce in China. Es enthält sieben Kapitel mit insgesamt 89 Artikel, die Vorschriften für E-Commerce-Betreiber, Verträge, Streitbeilegung und rechtliche Verantwortlichkeiten im Zusammenhang mit E-Commerce-Geschäften festlegt. Das Gesetz legt mehr Nachdruck auf die Pflichten und Auflagen der E-Commerce-Betreiber und stärkt 
gleichzeitig den Schutz der Verbraucher*innen. Insbesondere sind die Betreiber von E-Commerce-Plattformen verpflichtet, bei der Registrierung von echten Namen die Cybersicherheit zu gewährleisten, die Sicherheit der Person, des Eigentums der Verbraucher sowie geistiges Eigentum zu schützen. Das Gesetz verbietet es E-Commerce-Betreibern mit marktbeherrschender Stellung, den Wettbewerb auszuschließen oder einzuschränken. Plattformbetreiber, die Transaktionen auf ihren Plattformen in unangemessener Weise einschränken, können mit einer Strafe von 500.000 Yuan (etwa 65.000 Euro), in schweren Fällen bis zu 2 Millionen Yuan, belegt werden. Eine ähnlich hohe Strafe kann auch gegen Plattformbetreiber verhängt werden, wenn sie es versäumen, die notwendigen Schritte gegen die Verletzung von Rechten des geistigen Eigentums durch Händler auf ihren Plattformen zu unternehmen, die ihnen bekannt sind oder bekannt sein sollten (Fung Business Intelligence 2018, S. 57).

Obwohl dieses Gesetz sehr weitereichend aussieht, werden auch hier wieder primär die Firmen und die Nutzer haftbar gemacht und nicht die Regierungsbehörden (Shi-Kupfer und Chen, Massenhaft Nutzer - mangelhafter Datenschutz, 2017, S. 2).

\section{Das chinesische Social Credit System}

Die chinesische Regierung ist auf den reibungslosen Aus- und Aufbau eines nationalen Datennetzwerkes angewiesen. Dieses Datennetzwerk bildet den Grundpfeiler des von der Zentralregierung vorangetriebenen gesellschaftlichen Bonitätssystems (Social Credit System), mit dem das Verhalten von Firmen und Einzelpersonen überwacht und gesteuert werden soll. Mit Strafen und Belohnungen will Peking Unternehmen und Bürger*innen zu regelkonformem Verhalten erziehen. Das Social-Credit-System befindet sich derzeit in der Pilotierung, 2020 soll es flächendeckend eingeführt werden. Obwohl zur Zeit die Teilnahme daran noch freiwillig ist, soll es angeblich schon von über $50 \%$ genutzt werden (Ryssel 2019). Das Ganze soll folgendermaßen funktionieren: Jeder Chinese, jede Chinesin und jedes Unternehmen startet mit 1000 Punkten. Für „Wohlverhalten“ baut man Punkte auf, wegen „Fehlverhaltens“ verliert man Punkte. Der höchste Wert liegt bei 1300 Punkten, der niedrigste Wert beträgt 600 Punkte (Siehe Abb. 2.4).

Zur Berechnung der Punkte wird das System die riesigen Datenmengen aus den zahlreichen Quellen nutzen, die der Regierung zur Verfügung stehen. Das sind einerseits traditionelle Quellen wie Kreditbewertungen, Strafregister, Meldedaten oder Schulzeugnisse. Ebenso fließen aber auch Daten aus digitalen Speichern ein, etwa die Suchbegriffe, die die Person im Internet eingegeben hat, ihre Shopping-Vorlieben in Internetläden oder die Kommentare, die sie in Sozialen Medien geposted hat. Außerdem wird ein großer Teil des öffentlichen Raums in China kameraüberwacht. Mithilfe von Gesichtserkennung können etwa Verkehrssünder auf diese Weise identifiziert und ihre Sozialkredite abgewertet werden. Eine künstliche Intelligenz verarbeitet die Datenströme und berechnet für jeden Chinesen und jede Chinesin den individuellen Punktestand.

„Wohlverhalten“ ist z. B. die Pflege älterer Familienangehöriger, positiv auf die Nachbarschaft einzuwirken, Blut zu spenden, aber auch, sich lobend über die Regierung in 
Abb. 2.4 Das Soziale Kreditsystem in China (Benrath und Bartsch, Asien in Zahlen - Teil II - Punktabzug für zu seltene Besuche bei den Eltern, 2018)

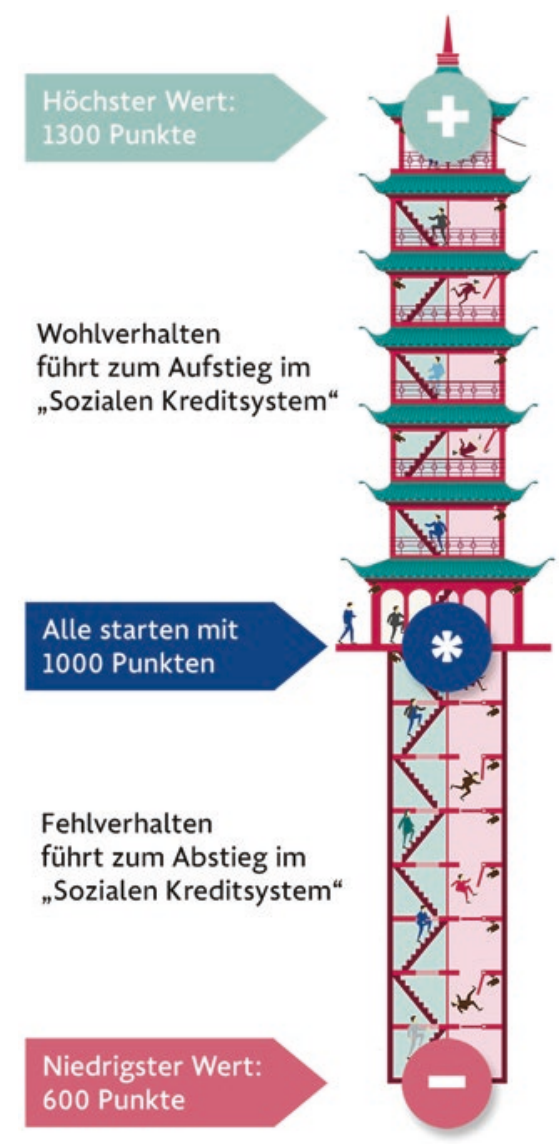

Sozialen Medien zu äußern. Als „Fehlverhalten“ wird angesehen, zum Beispiel bei Rot über die Ampel zu gehen oder betrunken Auto zu fahren, in Online-Spielen zu betrügen, aber auch, sich regierungskritisch in Sozialen Medien zu Wort zu melden oder ,illegal“ gegen die Behörden zu demonstrieren.

Dass diese Überwachung im Verkehr bereits live geschaltet ist, zeigt Abb. 2.5. Die Aufnahme hat die Autorin im November 2019 auf einer ganz normalen Straße in Peking aufgenommen. An der Kreuzung filmen Kameras, welche Fußgänger*innen bei Rot über die Ampel gehen. Deren Gesichter werden direkt an der Straße auf einer großen Videowand gezeigt. Die Augen der Verkehrsünder*innen werden dabei noch mit einem schwarzen Balken belegt, so dass nicht unmittelbar erkenntlich ist, welche Person sich gerade regelwidrig verhalten hat. Der Film, aus dem die Bilder kopiert sind, findet sich hier: 


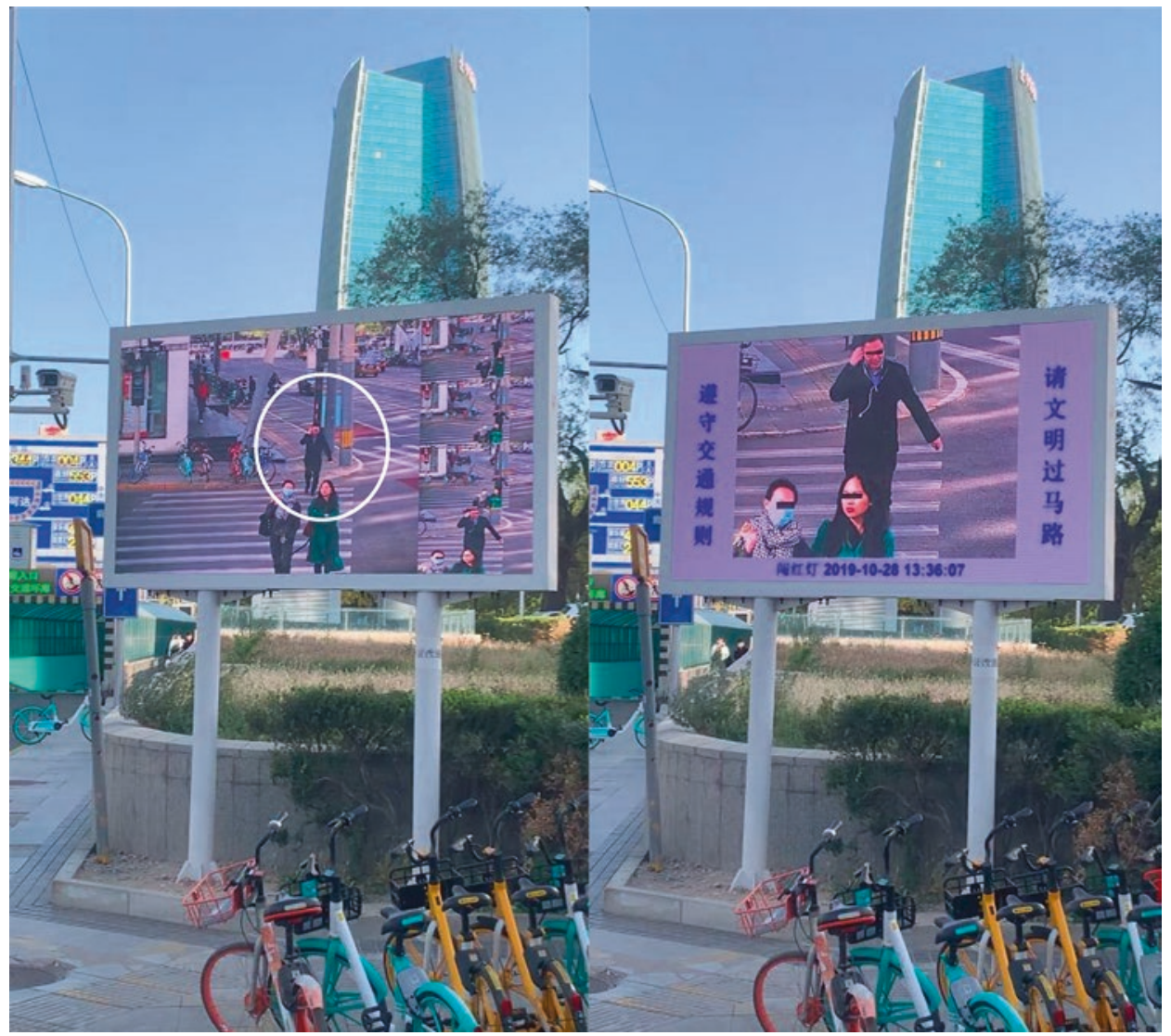

Abb. 2.5 Verkehrs-Videoüberwachung an einer normalen Kreuzung in Peking November 2019 (eigene Darstellung)

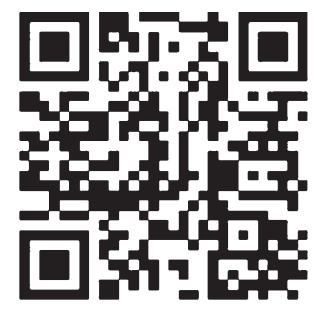

Ein hoher Punktestand im zukünftigen Social-Credit-System wird mit vielen Vorrechten belohnt: Vorrang bei Schulzulassungen und der Vergabe von Arbeitsplätzen, leichterer Zugang zu Krediten oder zu kostenlosen Fitnesseinrichtungen, kürzere Wartezeiten in Krankenhäusern und ähnliches mehr. Ein Chinese oder eine Chinesin mit niedrigem Punktestand hat einen schwereren Zugang zu Krediten, zu Flügen und Bahnangeboten und muss mit möglichen Sperren für bestimmte Berufe im öffentlichen Dienst und einem ein- 
geschränkten Zugang zu öffentlichen Dienstleistungen rechnen. Aus westlicher Sicht besonders besorgniserregend ist die Idee, Menschen mit geringem Punktestand mit Name, ID und Foto im öffentlichen Raum an den Pranger zu stellen oder der Plan eine Tonwarnung vor dem Freizeichen einzubauen, wenn man eine entsprechende Person anrufen will (Benrath und Bartsch, Asien in Zahlen - Teil II - Punktabzug für zu seltene Besuche bei den Eltern, 2018). Erste Nachteile wurden schon eingeführt: 17,5 Millionen Chinesen und Chinesinnen durften im Jahr 2018 nicht fliegen, 5,5 Millionen nicht mit dem Schnellzug fahren, weil ihre Sozial-Punkte zu niedrig waren (Wurzel 2019). Chines*innen, die die Sicherheits-App von Qihoo 360 auf ihrem Smartphone installiert haben, sollen in Zukunft gewarnt werden, wenn sie es mit jemanden am Telefon zu tun haben, der auf der Schwarze Liste des Bezirksgerichts Chaoyang steht (Trivium China 2019, S. 44). Auch die wichtigsten Tech-Firmen Chinas sind auf die eine oder andere Art und Weise am System beteiligt:

„That is to say: We haven't found any evidence to suggest that behavioral shopping data (like what items people purchase online), and social media data (like what people say in chat rooms), will feed directly into the national social credit database. You won't get a black mark on your record for buying cigarettes. However, private tech platforms are participating in the social credit system, particularly in the areas of fintech and ecommerce. It's a little difficult to tease the concepts of fintech and ecommerce apart, because many of China's major ecommerce players are also China's biggest online lenders, and they operate financial services platforms“" (Trivium China 2019, S. 44). Trivium China zufolge hat beispielsweise Alibaba 2015 ein Abkommen mit dem Obersten Volksgerichtshof unterzeichnet. Alibaba schränkt danach Nutzer*innen, die auf der schwarzen Liste der säumigen Zahler des Gerichts stehen, im Kauf von Luxusprodukten ein. Zu den anderen großen Technologieunternehmen, die sich an diesem System beteiligen, gehören Suning Electronics, Jingdong Finance, der Netzwerksicherheitsgigant Qihoo 360, Tencents WeBank, die Bike-Sharing-Plattform Mobike und CTrip (Trivium China 2019, S. 44).

Auch das Punktesystem stößt auf vergleichsweise wenig Gegenwehr bei der Bevölkerung: Eine repräsentative Befragung von 2200 Chinesen*innen durch die Freie Universität Berlin ergab kürzlich, dass 80 Prozent der chinesischen Bevölkerung Sozialkreditsysteme befürworten. Ebenfalls 80 Prozent ließen sich auch jetzt schon, bevor das System flächendeckend eingeführt wird, freiwillig bewerten (Benrath und Bartsch, Asien in Zahlen - Teil II - Punktabzug für zu seltene Besuche bei den Eltern, 2018).

Eine solches System, aufgebaut auf der Kombination von verschiedenen persönlichen Daten, kann es nach dem aktuell geltenden DGSVO in Europa nicht in gleicher Weise geben: Gem. Art. 6 Abs 1 lit. e) DSGVO müsste zunächst eine Rechtsgrundlage im Unions- oder Mitgliedsstaatenrecht geschaffen werden, welche die Datenverarbeitung für ein Sozialpunktesystem rechtfertigt. Ein solches Gesetz wiederum wäre in Deutschland nur im Rahmen des Grundgesetzes, Art. 2 Abs. 1 i.V.m. Art. 1 Abs. 1 GG, möglich. Auf europäischer Ebene wäre Art. 8 GRCh zu beachten. Das Ziel des Sozialpunktesystems und die Art und Weise, wie es in China umgesetzt wird, ist mit diesen Grundsätzen nicht vereinbar. Es fehlte den Behörden somit an einer geeigneten Rechtsgrundlage (Ryssel 2019). Dennoch sind Bewertungen, die ein Wohl- oder Fehlverhalten anzeigen, in Europa durch- 
aus üblich, in Deutschland etwa beim Bewerben um eine Wohnung oder beim Abschluss eines Telefonvertrages: Das Schufa-Auskunftssystem beispielsweise ist ein Punktesystem, in dem das bisherige Kreditverhalten einer Person überprüft und transparent gemacht wird.

China katapultiert sich also gerade in die Pole-Position auf dem Weg zur führenden Wirtschaftsmacht des 21. Jahrhunderts. Ein für europäische Verhältnisse laxes Personendatenschutzgesetz auf der einen und das sehr strikte Landesdatenschutzgesetz auf der anderen Seite macht China zum Land des Weltmeisters im Datensammeln. Kombiniert China diese Daten nun noch sinnvoll mit einem Analyse- und Lernwerkzeug von Weltklasse, einer entsprechenden KI, werden es die westlichen Länder schwer haben, mitzuhalten. Das schauen wir uns im nächsten Kapitel an.

\subsection{China: „Der Westen“ - KI-Strategien eines Staates}

China entwickelt sich zu einem „AI-first“-Staat und es entwickelt sich schnell: Eine große Menge an zentral und dezentral gesteuerten Strategien und taktischen Maßnahmen sind darauf angelegt, dass China im Bereich KI führend wird. Diese Ausrichtung auf KI wird in China, aller Voraussicht nach, schnellere und stärkere Auswirkungen auf die Wirtschaft und das Leben normaler Bürger*innen haben als in westlichen Staaten. Denn anders als im Westen, wo es eine klare Trennung zwischen Regierung, Gesellschaft und Wirtschaft gibt, basiert das chinesische System auf einer Symbiose dieser drei Bereiche. Alle drei sind dadurch schneller in der Lage, einander so zu stimulieren, dass gemeinsame Ziele besser erreicht werden können. Dass diese Symbiose auf Kosten von persönlichen Datenschutzrechten und anderen Bürgerrechten gehen kann, mag aus demokratisch geprägter, westlicher Sicht von Nachteil sein, ändert aber wenig an der eben getroffenen Aussage.

Die chinesische Staatsführung hat 2015 und 2017 die drei für unsere Diskussion wichtigsten Pläne bis 2025, bzw. 2050, vorgestellt. Diese Pläne sollen kurz im Bereich Wirtschaft und KI zusammengefasst werden. ${ }^{2}$ Zum einen wird deutlich, dass China den Anspruch hat, bis 2050 die global führende Macht zu werden und zum anderen, dass KI dabei eine Schlüsselrolle einnehmen soll.

\section{Der sogenannte „Made in China 2025“ Plan des Ministerpräsidenten Li Keqiang}

Dieser Plan von 2015 (Staatsrat der Volksrepublik China 2015), den ich hier kurz zusammenfassen werden, soll nach eigener Aussage die Strategie Chinas in bezug auf das ver-

\footnotetext{
${ }^{2}$ Die ursprünglich in Chinesisch veröffentlichen Reden und Anordnungen der Regierung wurden in englischen Übersetzungen recherchiert und von den Autoren hier ins Deutsche übersetzt. Obwohl diese Recherche mit großer Sorgfalt erfolgte, kann nicht ausgeschlossen werden, dass es zu Übersetzungsfehlern gekommen ist. Ich gebe deshalb immer auch die offizielle Originalquelle an, unter der der chinesische Text zu finden ist.
} 
arbeitende Gewerbe für die kommende Dekade ausformulieren (Staatsrat der Volksrepublik China 2015, S. 1): ${ }^{3}$

Angesichts von zunehmenden Umwelteinschränkungen und der Verknappung von Ressourcen, steigenden Kosten für Arbeit und Produktion sowie nachlassenden Investitionen und Exporten könne ein ressourcen- und investitionsintensives Entwicklungsmodell, das auf Expansion ausgerichtet sei, nicht aufrechterhalten werden. China müsse daher sofort die Entwicklungsstruktur anpassen und die Qualität der Entwicklung erhöhen. Das verarbeitende Gewerbe sei der Motor, der die sogenannte „Neue chinesische Wirtschaft“ antreiben werde (Staatsrat der Volksrepublik China 2015, S. 2). Aktuell sei man aber im Rückstand, verglichen mit den Leistungen des verarbeitenden Gewerbes sogenannter entwickelter Länder. Dieser Bereich der chinesischen Wirtschaft sei zwar groß, aber qualitativ noch nicht ausreichend entwickelt. (Staatsrat der Volksrepublik China 2015, S. 4).

Strategisch sollen folgende drei Stufen hintereinander erreicht werden: (Staatsrat der Volksrepublik China 2015, S. 7 - 9)

In der ersten Stufe soll China in zehn Jahren zu einer wichtigen Produktionsmacht aufsteigen: Bis 2020 will man die Industrialisierung erreichen, die Fertigungskraft konsolidieren und die Digitalisierung der Fertigung erheblich vorantreiben. Bis 2025 soll sich die Gesamtqualität der Fertigung und die Innovationskapazität deutlich verbessern, die Arbeitsproduktivität insgesamt soll sich erheblich erhöhen und die Integration der IT in die Industrie ein fortgeschrittenes Niveau erreichen. Die zu erreichenden Wirtschaftsindikatoren und ihre Wachstumsraten bis 2025 werden ebenfalls definiert. Hierbei wird z. B. angestrebt, dass die Breitbandabdeckung für das Internet von 37 \% im Jahr 2013 auf 82 \% im Jahr 2025 ansteigen soll.

In der zweiten Stufe bis 2035 soll das chinesische verarbeitende Gewerbe ein mittleres Niveau unter den Weltherstellern erreichen.

In der dritten Stufe bis zum Jahr 2049, dem hundertsten Jahrestag der Gründung des sogenannten „New Chinas“, also der Volksrepublik China, soll Chinas Status im verarbeitenden Gewerbe konsolidiert und China zum führenden Land unter den Fertigungsländern der Welt geworden sein.

Die drei wichtigsten politischen Instrumente sind dabei Technologieaustausch mit ausländischen Unternehmen für den Marktzugang zu China, beschränkter Zugang für Ausländer und der Aufkauf von ausländischen Unternehmen und deren Knowhow. ${ }^{4}$ Die zehn strategischen Wirtschaftsbereiche, auf die man sich fokussieren will, sind (Benrath et al. 2018):

- Fortgeschrittene IT

- Automatisierung \& Robotik

\footnotetext{
${ }^{3}$ Der Originaltext findet sich hier: http://www.gov.cn/zhuanti/2016/MadeinChina2025-plan/ index.htm.

${ }^{4}$ Beispiele dafür sind Lenovos Kauf von Teilen von IBM oder der Carve-Out von Teilen Osrams zu Ledvance und der Verkauf von Ledvance an ein chinesisches Konsortium.
} 
- Luftfahrt und Luftfahrtausrüstung

- Maritime Ausrüstung und High-Tech-Versand

- Moderner Schienenverkehr

- Fahrzeugtechnik mit neuer Energie

- Energieversorgung

- Landwirtschaftliche Ausrüstung

- Biopharma und fortgeschrittene medizinische Produkte

- Neue Materialien

Anspruchsvoll sind auch die $\mathrm{CO}_{2}$-Ziele, die Peking ausgerufen hat: Innerhalb von 10 Jahren, von 2015 bis 2025, will China seine $\mathrm{CO}_{2}$-Emissionen um 40 Prozent reduzieren. Zum Vergleich: Deutschland plant, seine Emissionen in einem Zeitraum von 30 Jahren, von 1990 bis 2020, um 40 Prozent zu reduzieren, ein Vorhaben, dass es aller Voraussicht nach nicht erreichen wird (Benrath et al. 2018).

Interessant ist außerdem, dass in diesem Text kein einziges Mal das Wort Künstliche Intelligenz genannt wird, sondern damit verwandte Begriffe wie „IoT“ (Internet of Things) und „Digitalisierung“. Dass nur zwei Jahre später ein ganzes Strategiepapier zu KI erscheint, zeigt, wie dynamisch China sich auf Regierungsebene den schnell weiterentwickelnden Marktbedingungen anpasst (Webster et al. 2017).

\section{Xis Rede auf dem 19. CPC Nationalkongress am 18.10.2017 (Xi 2017)}

In dieser Rede stellt Xi einen 3-Stufen-Plan für China vor. In der ersten Stufe wolle man bis 2020 eine insgesamt mäßig prosperierende Gesellschaft schaffen, in der zweiten Stufe bis 2035 China grundsätzlich modernisieren und bis 2050 aus China ein auf allen Gebieten hervorragendes, modernes sozialistisches Land machen.

Ziele, die bis 2035 erreicht sein sollen, sind:

- „China’s economic and technological strength has increased significantly. China has become a global leader in innovation.

- The rights of the people to participate and to develop as equals are adequately protected. The rule of law for the country, the government, and society is basically in place. Institutions in all fields are further improved; the modernization of China's system and capacity for governance is basically achieved.

- Social etiquette and civility are significantly enhanced. China's cultural soft power has grown much stronger; Chinese culture has greater appeal.

- People are leading more comfortable lives, and the size of the middle-income group has grown considerably. Disparities in urban-rural development, in development between regions, and in living standards are significantly reduced; equitable access to basic pu-

\footnotetext{
${ }^{5}$ Die hier genutzte Quelle der englischsprachigen Übersetzung von Xis Rede ist Xinhua, die offizielle Nachrichtenagentur der Regierung der Volksrepublik China. Insofern darf davon ausgegangen werden, dass die englische Übersetzung dem offiziellen Inhalt der Rede Xis entspricht.
} 
blic services is basically ensured; and solid progress has been made toward prosperity for everyone.

- A modern social governance system has basically taken shape, and society is full of vitality, harmonious, and orderly.

- There is a fundamental improvement in the environment; the goal of building a Beautiful China is basically attained“ (Xi 2017, S. 24-25)

Drei Dinge fallen hier auf: Zum einen wird der Plan wie schon das Strategiepapier zu „Made in China 2025“ mit klaren, messbaren Zielen verbunden. Zum zweiten sind die formulierten Ziele erneut nicht nur gesellschaftlicher oder wirtschaftlicher Natur, sondern allumfassender, da auch die Umwelt, das Regierungssystem, chinesische Kultur und das Rechtswesen mit einbezogen werden. Und zum dritten will China nun schneller, nämlich bis 2035, weltweit führend sein bei Innovationen. Noch 2015, also nur zwei Jahre vorher, wollte man bis 2049 führend sein.

Die Ziele, die China bis 2050 erreichen soll, sind noch anspruchsvoller:

- „New heights are reached in every dimension of material, political, cultural and ethical, social, and ecological advancement.

- Modernization of China's system and capacity for governance is achieved.

- China has become a global leader in terms of composite national strength and international influence.

- Common prosperity for everyone is basically achieved.

- The Chinese people enjoy happier, safer, and healthier lives.“ (Xi 2017, S. 25)

Auch hier fällt auf, dass die Ziele breit angelegt sind, allerdings auch weniger greifbar, vermutlich, weil 33 Jahre im Voraus geplant wird. Dennoch ist der Anspruch, führend in der Welt zu sein, klar erkennbar. Dass KI dabei eine wichtige Rolle spielen soll, geht aus der letzten der drei Quelle hervor:

\section{Plan des Zentralkomitees zu KI in China vom 08.07.2017 (Webster et al. 2017) ${ }^{6}$}

In diesem Plan erläutert das Zentralkomitee der Kommunistischen Partei Chinas die strategische Wichtigkeit von KI als grundsätzlich weltverändernd und essentiell für Chinas Entwicklung auf dem Weg zur führenden globalen Macht:

„The rapid development of artificial intelligence (AI) will profoundly change human society and life and change the world. To seize the major strategic opportunity for the development of AI, to build China's first-mover advantage in the development of AI, to accelerate the construction of an innovative nation and global power in science and technology, in accordance with the requirements of the CPC Central Committee and the State

\footnotetext{
${ }^{6}$ Der offizielle Text ist hier zu finden: http://www.gov.cn/zhengce/content/2017-07/20/content_5211996.htm.
} 
Council, this plan has been formulated.“(Webster et al. 2017). China geht also davon aus, dass KI die Welt grundlegend verändert wird.

Im Kapitel „Strategische Situation“, gleich zu Beginn des Dokumentes, wird folgendes Resümee gezogen:

- KI entwickele sich inhaltlich zu einer der wichtigsten Schlüsseltechnologien

- KI stehe im Fokus des internationalen Wettbewerbs und werde von allen entwickelten Ländern als strategische Technologie erkannt, die Wettbewerbsfähigkeit und die Verteidigung des eigenen Landes sicherzustellen. China müsse daher KI ebenfalls in dieser Weise strategisch nutzen

- KI sei der Motor für die weitere wirtschaftliche Entwicklung, der Haupttreiber für eine neue Runde innerhalb der industriellen Transformation

- KI biete neue Möglichkeiten für einen modernen sozialen Aufbau. China sei dabei, eine „mäßig prosperierende Gesellschaft“ zu formen mit großen Herausforderungen wie sie z. B. eine überalterte Gesellschaft und der Umweltschutz darstellten. KI könne breit eingesetzt werden in wichtigen Bereichen wie Bildung, Gesundheitswesen, Umweltschutz, Stadtplanung. KI nehme dabei eine ,unersetzliche Rolle bei der wirksamen Wahrung der sozialen Stabilität ein“

- Als disruptive Technologie berge KI jedoch auch selbst Risiken, die mitberücksichtigt werden müssten

- China sei noch nicht auf Augenhöhe mit den entwickelten Ländern bei der weiteren Erforschung von KI

Die deshalb aufgestellten Ziele und Maßnahmen geben die Richtung bis 2030, also für rund eine Dekade vor: Bis 2020 soll ,die gesamte Technologie und Anwendung von KI mit dem weltweit erreichten Niveau Schritt halten“. Woran man genau erkennen kann, dass dieser Zustand erreicht ist, wird ein detail erklärt, außerdem werden messbare Zahlen genannt. Die Größenordnung der Kernbranche von AI soll 150 Milliarden RMB übersteigen (rund 19,5 Milliarden Euro), verwandte Branchen sollen 1 Billionen RMB erreichen (rund 120 Milliarden Euro).

Bis 2025 sollen bedeutende Durchbrüche bei den grundlegenden Theorien zur KI erzielt werden. Einige Technologien und Anwendungen sollen dadurch ein weltweit führendes Niveau erreichen und die KI zum Hauptantrieb werden für Chinas wirtschaftliche Transformation und die Modernisierung seiner Industrie. Auch hier werden explizit die zu erreichenden Ziele formuliert und unter anderem auch Umsatzzahlen vorgegeben: Der Umfang der Kernbranche von AI soll mehr als 400 Milliarden RMB (52 Milliarden Euro) betragen, das Volumen verwandter Branchen wird 5 Billionen RMB (646 Milliarden Euro) übersteigen.

Bis 2030 sollen Chinas KI-Theorien, -Technologien und -Anwendungen ein weltweit führendes Niveau erreichen, so dass China zum wichtigsten KI-Innovationszentrum der Welt werde. Diesem Ziel und den damit verbundenen Auswirkungen auf die Wirtschaft will man näherkommen, indem man 1 Billion RMB in KI-Kernbranchen (129 Milliarden Euro) und 10 Billionen RMB in KI-verwandte Branchen (1,29 Billionen Euro) investiert. 
Für unsere weitere Diskussion relevant sind noch die vier Prinzipien, die proklamiert wurden. Diese sind: Führung in Technologie, Systementwicklung, Marktbeherrschung (ohne dass beschrieben würde, ob im In- oder Ausland) und Open-Source-Nutzung.

Die weiteren Ausführungen des Plans machen detaillierte Vorgaben, wie genau diese Ziele zu erreichen sind. Allein um zu verstehen, wie grundlegend diese Vorgaben sind, lohnt es sich, den Text komplett durchzulesen. Aus Gründen der Reduktion auf das Wesentliche unserer Diskussion zu KI im Marketing wird an dieser Stelle darauf verzichtet.

Insgesamt zeigen die Strategien zum verarbeitenden Gewerbe von 2015, zu KI als Schlüsseltechnologie und der Plan für China insgesamt, die beiden letzteren von 2017, dass China

- bei der Planung wichtiger Strategien immer den Dreiklang aus Regierung, Gesellschaft und Wirtschaft mit einbezieht und sich zum Ziel setzt

- sehr schnell ist bei der Anpassung von Vorgaben an neue, sich dynamisch entwickelnde Gegebenheiten

- über die in Europa und den USA üblichen Legislaturperioden hinaus plant, dies in der Regel in drei Schritten vollzieht, bis 2049 also in gut 3 Dekaden

- in Künstlicher Intelligenz die Schlüsseltechnologie für die positive Entwicklung aller Bereiche des Landes sieht und diese Technologie entsprechend unterstützen wird

Diese Unterstützung erfolgt unter anderem durch ein konsequentes finanzielles Engagement im eigenen Land, eine explizite Förderung von Startups in der ganzen Welt und eine schnellere (oder reduzierte) Bürokratie. Hinzu kommen die Ausrichtung des Bildungswesens auf für KI wichtige Fähigkeiten, vor allem mathematisch-naturwissenschaftlicher Natur und das gezielte Anwerben von KI-Talenten weltweit. Schauen wir uns das jetzt hintereinander an.

\section{Finanzielle Unterstützung im eigenen Land}

Zwar sehen, wie beschrieben, auch die führenden westlichen Industrienationen in KI eine der Schlüsseltechnologien dieses Jahrhunderts (FAZ 2018) und unterstützen sie mit finanziellen Mitteln - die EU z. B. bis Ende 2020 mit geplanten $20 \mathrm{Mrd}$. Euro aus privaten und öffentlichen Händen (John 2018), die deutsche Regierung bis 2025 mit 3 Mrd. Euro aus öffentlicher Hand (Heide 2018). Gegen die finanziellen Ressourcen, die China bereitstellen will, wirken diese Summen aber recht klein: China, das bis 2030 führend auf dem Gebiet der KI führend sein will, schätzt diese neue Branche auf einen Wert von 130 Milliarden Euro (Hua und Jahn 2018) und plant u. a. einen 1,76 Milliarden teuren KI-Gewerbepark in Peking (Neuerer 2018). 2017 hat China 8,7 \% der staatlichen Haushaltsausgaben daher in R\&D investiert, die USA dagegen nur 2,9 \% (Manuel 2019). Dies finanzielle Unterstützung geht gar nicht mal nur von der Zentralregierung aus, sondern von den vielen lokalen Funktionären, die darum wetteifern, der Partei zu zeigen, wie gut sie in der lokalen Umsetzung sind. Ein gutes Beispiel dafür sind die Investitionen in Xiong'an, eine Region etwa $80 \mathrm{~km}$ entfernt von Peking, die so umgestaltet wird, dass sie, wenn alles nach Plan läuft, die weltweit erste Stadt sein wird, die speziell auf autonom fahrende Autos ausgerichtet ist. Baidu hat einen Vertrag mit der lokalen Administration 
geschlossen, dort eine solche KI-Stadt zu entwickeln, mit Verkehrsmanagement, autonomen Fahrzeugen und bestimmten Umweltschutzmaßnahmen. Schätzungen gehen von einer Investition von 583 Milliarden US-Dollar in die Infrastruktur von Xiong'an aus (Lee 2018, S. 133 - 134).

\section{Globale Unterstützung von Startups}

Untersuchungen von Investitionen in Startups im Bereich der Künstlichen Intelligenz zeichnen ein ähnliches Bild: Die Finanzierung von Private Equity-Firmen in Startups in China nimmt in den letzten Jahren deutlich an Fahrt auf: War der Anteil von chinesischen Startups bei Private Equity-Firmen 2015 noch bei nur mageren $3 \%$, lag er 2017 bereits bei $36 \%$. Damit liegt China auf Platz zwei hinter den USA. Die Halbjahreszahlen für 2018 deuten bereits an, dass sich der Trend fortsetzt (OECD 2018).

China investiert jedoch nicht nur in China, sondern auch global in Startups und überholt dabei sogar schon den bisherigen Platzhirschen, die USA, mit einem Anteil von $48 \%$ (Abb. 2.6).

Abb. 2.7 zeigt graphisch die aktuellen Größenverhältnisse. China und Europa sind dem Augenschein nach bei der Unterstützung von KI mit Geld vergleichsweise klein, aber China holt deutlich auf: Alleine von 2014 bis 2017 hat sich der Anteil Chinas an der globalen Gesamtzahl von Höchstleistungscomputern von rund $15 \%$ auf fast $32 \%$ mehr als verdoppelt. Der Anteil der mobilen Nutzer weltweit in China mit $20 \%$ versus den USA mit $6 \%$ führt man auf den ersten Blick auf die größere Bevölkerung zurück (1,3 Milliarden versus 327 Millionen). Anteilig gibt es in den USA jedoch noch mehr Mobiltelefonnutzer pro Einwohnerzahl als in China. Allerdings habe ich bereits dargelegt, dass bei KI die schiere Menge an Echtzeitdaten über Konsumenten den KI-Wettstreit entscheiden kann. Und da hat heute schon China ,die Nase vorn“.

Abb. 2.6 Prozentualer Anteil des genannten Landes am Funding-Budget von KIStartups global 2017. (Eigene Abbildung nach (OECD 2018))

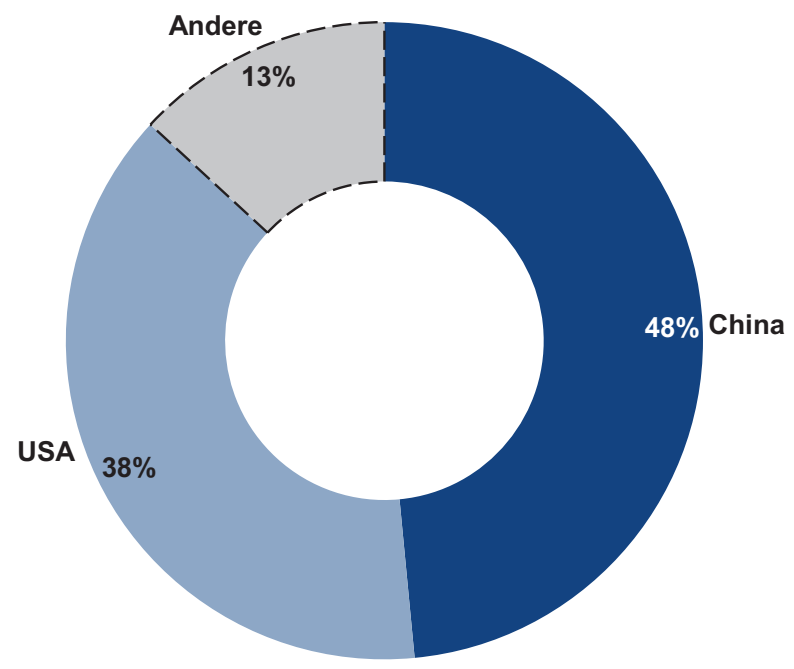




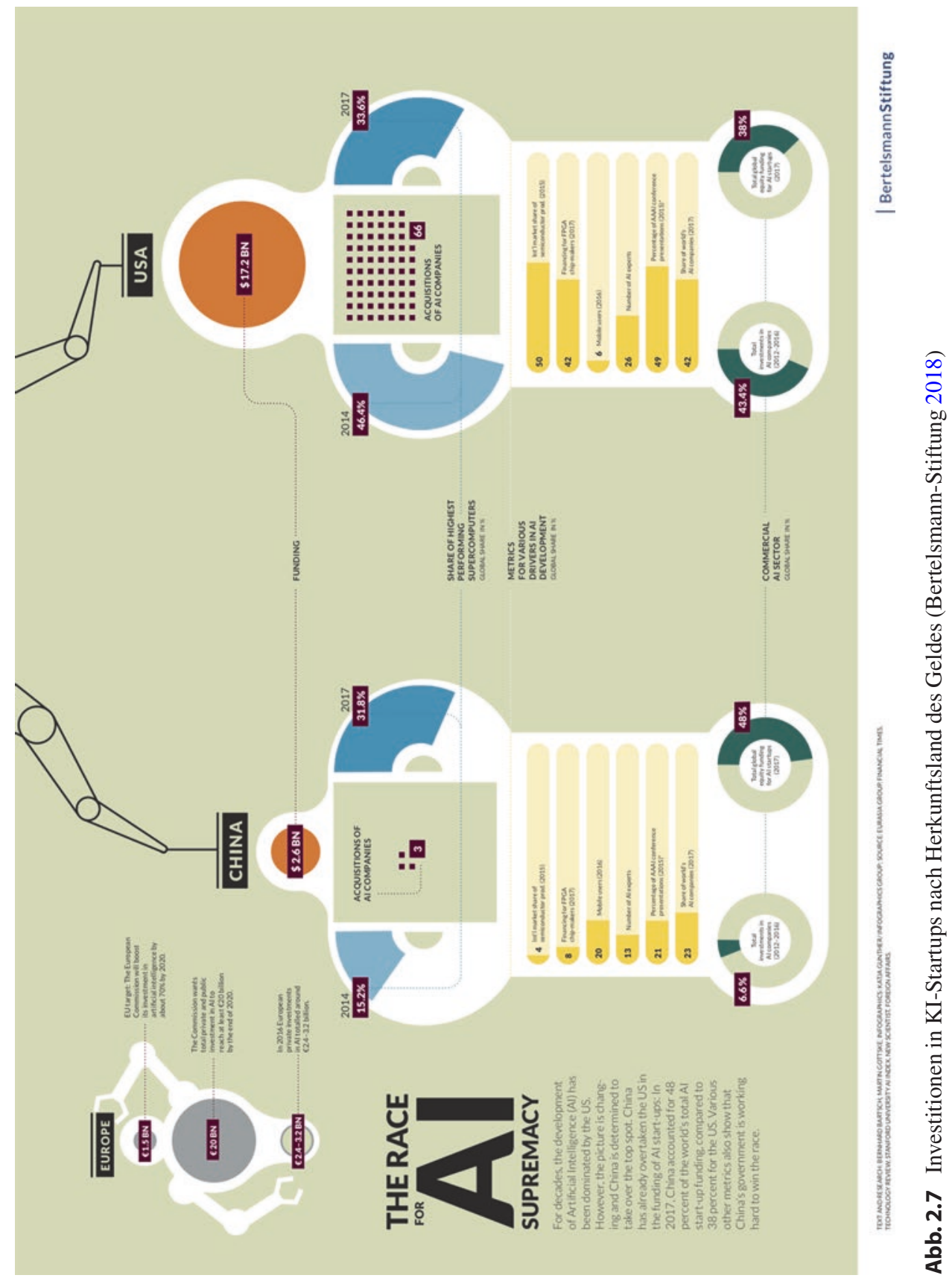




\section{Unbürokratische Bürokratie}

Man muss nicht viel Phantasie haben, um sich vorzustellen, dass ein Staat, der ein Bonus/ Malus-System für Unternehmen und Bürger*innen eingeführt, ein vergleichsweise laxes Persönlichkeitsdatenschutzgesetz und klare 5-Jahrespläne inkl. Budget für das Thema KI entwickelt und kommuniziert hat, in der Lage ist, den entsprechenden Firmen und Startups rund um KI bei Genehmigungen und anderen bürokratischen Prozessen bevorzugt weiterzuhelfen. An zwei Beispielen wird dies exemplarisch deutlich:

\section{Die Planstadt Shenzhen}

Shenzhen, bis dahin eher landwirtschaftlich geprägt, wurde unter Deng Xiaoping im Mai 1980 zur ersten Sonderwirtschaftszone Chinas, unter anderem wegen seiner günstigen Lage direkt gegenüber von Hongkong. Bis dahin war die Stadt rund 300.000 Einwohner groß. Seitdem Shenzhen Sondergenehmigungen und Unterstützung vom Staat erhält, ist die Stadt bis 2017 auf 11 Millionen Einwohner angewachsen. Sie besitzt eine eigene Börse. Nicht nur einige der wichtigsten chinesischen Hightec-Firmen, wie etwa BYD, Dingoo, Gionee, Hasee, Huawei, Skyworth, Tencent, Xunlei oder ZTE siedelten sich dort an, auch viele ausländische IT-Unternehmen haben Niederlassungen in der Stadt. Dazu zählen beispielsweise Siemens und der weltgrößte Elektronikhersteller Foxconn, der mit mehr als 300.000 Mitarbeiter*innen iPods für Apple und Bauteile für Sony, Nintendo und Hewlett-Packard herstellt (Wikipedia 2019a, b).

Ganz nebenbei hat Shenzhen auch die erste flächendeckende Ausrüstung mit Gesichtserkennungskameras weltweit; die Stadt beobachtet ihre Bewohner rund um die Uhr (Lohse 2018). Die dabei gesammelten Daten werden in einem System namens „Skynet“ zentral gesammelt. Bereits heute ist die Polizei in Shenzhen damit in der Lage, per Foto eines Gegenübers und dem Abgleich mit einer App, den Betreffenden zu identifizieren. Selbst, wenn er oder sie den Ausweis nicht dabeihat, oder nicht zeigen will, kann sie feststellen, ob er oder sie polizeilich gesucht wird (Orth 2019). Alle gesammelten Daten werden in einer Schaltzentrale der Stadtverwaltung zusammengeführt. Hier ist dokumentiert, wie die Wasser-, Strom- und Gesundheitsversorgung aktuell aussieht und bei welchen Häusern illegale Bautätigkeiten stattfinden. Über Bodycams der Polizist*innen und Mitarbeiter*innen werden auch Nebenstraßen kontinuierlich überprüft. Wer heute als Autofahrer*in an einem Zebrastreifen in Shenzhen nicht anhält, um Fußgänger*innen über die Straße zu lassen, bezahlt direkt, in Echtzeit, die dafür vorgesehene Strafe per App im Smartphone - so vernetzt sind Autodaten und Smartphonedaten in Echtzeit.

Abb. 2.8 zeigt die beschriebene Schaltzentrale der Stadtverwaltung im Jahr 2019. Der wirtschaftliche Erfolg bleibt dabei nicht aus. Bereits heute hat Shenzhen dieselbe Wirtschaftsleistung eines Landes wie Schweden (Wolff und Yogeshwar 2019).

\section{Der Bejing Daxing International Airport}

Peking hat gerade in nur 4 Jahren Bauzeit und Baukosten von 10 Milliarden Euro (Ankenbrand, China will 2019 weltgrößten Flughafen eröffnen, 2017b) einen zweiten in- 


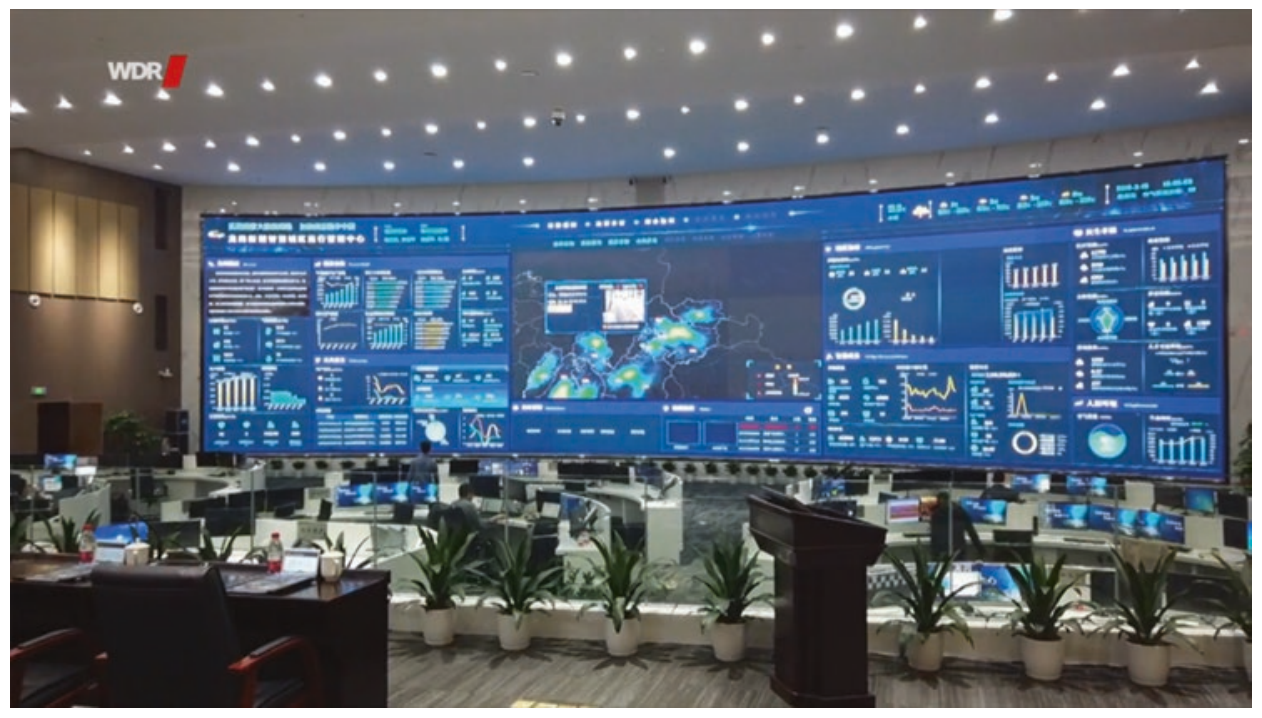

Abb. 2.8 Schaltzentrale der Stadtverwaltung Shenzhen (Wolff und Yogeshwar, 2019)

ternationalen Flughafen errichtet. Dieser Flughafen ist der nach Fläche größte weltweit und etwa doppelt so groß wie der geplante neue Flughafen in Berlin (BER). Die geplanten Fluggastzahlen sollen den bisher größten Flughafen der Welt, Atlanta, übersteigen. Der Zeitplan wurde bis auf wenige Monate eingehalten. Der Bau dieses Flughafens ist nicht nur ein Prestigeobjekt, sondern war auch wirtschaftlich nötig geworden, da der alte Flughafen bereits aus allen Nähten platzt und die Anzahl der Passagiere weiterwachsen wird. Er ist Teil eines großen Umstrukturierungsprojektes für Peking. Peking soll nur noch die für eine Hauptstadt üblichen Aufgaben übernehmen, wie etwa die Staatsregierung, internationale Kommunikation, Forschung und Entwicklung. Alles anders soll ausgelagert werden in das Umland, in dem eine neue Metropolregion, ,JingJin-Ji“ genannt, entsteht (Ingenieur.de 2019). Es liegt nahe anzunehmen, dass hier die Schnelligkeit von Genehmigungen eine Priorität für alle Behörden ist, die mit dem Bau beschäftigt sind. Im Vergleich zu den Auflagen, Verzögerungen und Kosten des Berliner Flughafens ist die chinesische Geschwindigkeit sehr hoch: Der Berliner Flughafen wurde 1997 genehmigt, der Spatenstich folgte 2006, die Fertigstellung war für 2011 geplant, sollte also auch innerhalb von 5 Jahren erfolgen (Stern 2019). Mit einem Bauvolumen von ursprünglich 2 Milliarden Euro soll die Eröffnung nun bis zum 31.12.2021 stattgefunden haben. Die Kosten belaufen sich nach Schätzungen vom Februar 2018 auf 6,44 Milliarden Euro, sind also mehr als dreimal so hoch wie geplant (Hartl 2019). Der Hauptgrund für die bislang rund 8 Jahre dauernde Bauverzögerung liegt in der fehlerhaften Bauausführung, die einige wichtige Bestimmungen, z. B. beim Brandschutz, nicht erfüllt. Selbstverständlich geht Personenschutz vor Prestigegewinn. Als Laie kann man sich jedoch des Eindrucks nicht erwehren, dass die Zusammenarbeit von Behörden und Bauleitung durchaus mehr Hand in Hand gehen könnte. Beim Bejing Daxing International Airport war dies vermutlich gewährleistet. 


\section{Investitionen in Bildung}

Der KI-Plan der Regierung von 2017 sieht explizit vor, dass in Bildung und Ausbildung von KI investiert werden soll, (Webster et al. 2017) wörtlich aus dem Chinesischen übersetzt steht dort:

\section{„Construct an AI academic discipline}

Improve the disciplinary layout of the AI domain. Establish AI majors. Promote the construction of a discipline in the domain of AI. Establish AI institutes as soon as possible in pilot institutions. Increase the enrollment places for masters and $\mathrm{PhDs}$ in working in $\mathrm{AI}$ and related disciplines. Encourage colleges and universities to broaden the content of AI professional education on an original basis. Create a new model of ,AI $+\mathrm{X}^{\prime}$ compound professional training, attaching importance to cross-integration of professional education for AI and mathematics, computer science, physics, biology, psychology, sociology, law, and other disciplines. Strengthen cooperation in production and research. Encourage universities, research institutes, enterprises and other institutions to carry out the construction of an AI discipline."

In Summe sollen also AI-Universitätsabschlüsse und AI-Universitätsinstitute geschaffen werden sowie Ausbildungen von „KI + X“, die KI mit Mathematik, Informatik, Physik, Biologie, Psychologie, Soziologie, Recht und andere Disziplinen kombinieren. AuBerdem wird dazu angehalten, Produktion und Forschung bei KI stärker zu verknüpfen.

Die ersten sichtbaren Erfolge dieser spezifischen Ausbildungen in China werden sicherlich noch ein paar Jahre auf sich warten lassen werden. Allerdings kann man schon heute absehen, dass die Investitionen der letzten Jahre in das Bildungssystem ein gutes Fundament darstellen, um darauf aufbauend junge Talente in KI auszubilden:

China verbessert offenbar seit Jahren die Schulbildung und seine Universitäten. Der „Bertelsmann Tranformationsindex“ (BTI) attestiert China im Bereich „Bildungspolitik/ Forschung und Entwicklung“ im Jahr 2006 sechs von 10 möglichen Punkten, 2010 sieben und 2016 schon acht von 10 „Bildungspunkten“. Damit liegt China vor Staaten wie Brasilien, Indien, Russland und Südafrika (Bertelsmann-Stiftung 2018). Im neusten BTI erreicht China erneut acht von 10 Punkten. Vergleiche mit Deutschland oder den USA können leider nicht gezogen werden, da der BTI diese Länder nicht mit einbezieht (Bertelsmann-Stiftung 2006-2018).

Die positiven Ergebnisse der Bildungspolitik sind auch sonst sichtbar: Im aktuellsten globalen Pisatest von 2015/2016 führt China vor Deutschland und den USA. Während China und Deutschland sich von 2010 bis 2015 verbesserten, fallen die USA sogar weiter ab (Siehe Abb. 2.9). Allerdings muss man die Zahlen mit Vorsicht genießen. Der Pisatest weist für China mehrere Regionen aus: Shanghai, Hongkong und die Sonderverwaltungszone Macao. Die Zahlen des Pisa-Testes für Shanghai 2009 und 2012, hier lag Shanghai auf Platz 1, sollen nicht repräsentativ sein, weil sie lediglich an Eliteschulen erhoben worden seien (Erling 2018). Daher habe ich diese für die Abbildung bewusst nicht ausgewählt. Außerdem muss darauf hingewiesen werden, dass das primäre offizielle Bildungsziel Chinas, hier formuliert von Xi, weiterhin sei, Erbauer des Sozialismus und Nachfolger heranzuziehen, die die Auferstehung Chinas als großer Nation beförderten. Lehrer hätten als „Ingenieure der Seele“ den Patriotismus der Jugend zu wecken (Erling 2018). Der Staat 


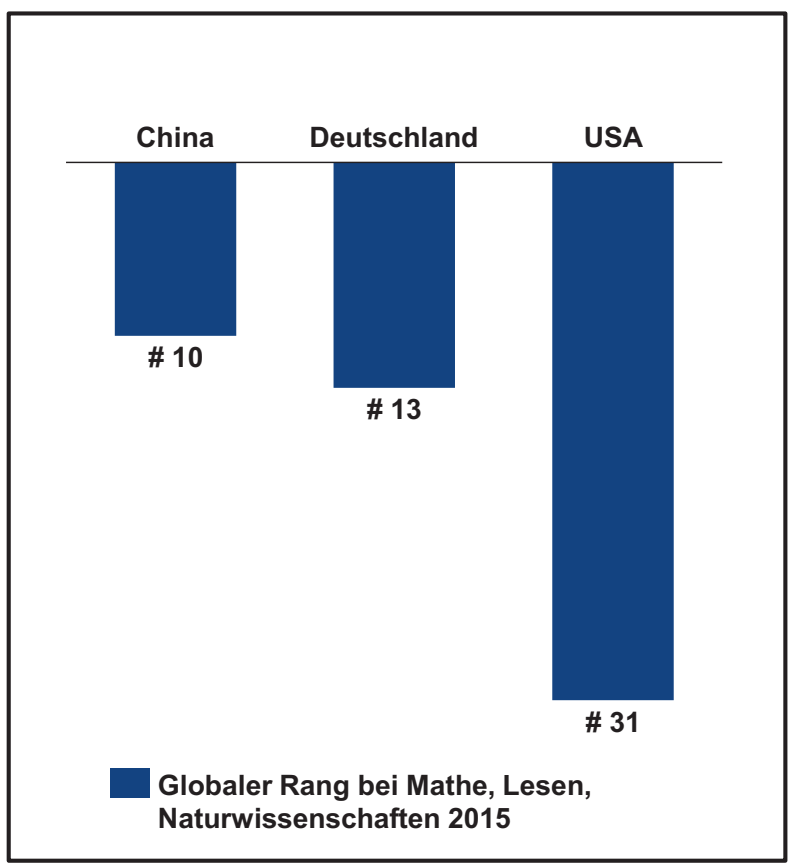

Veränderung 2010 - 2015 basierend auf der erreichten

Punktezahl, gerundet

China

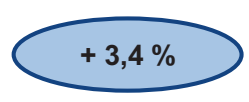

Deutschland $+4,3 \%$

USA

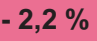

Abb.2.9 PISA Ergebnisse China, Deutschland, USA 2015. (Eigene Darstellung nach (OECD 2016))

dämmt folglich derzeit offenbar die privaten Initiativen der boomenden Nachhilfeindustrie wieder ein. Diese Branche ist in den vergangenen Jahren deutlich gewachsen. Es gibt 382.000 private Organisationen in China, die auf außerschulische Nachhilfe und Fortbildung spezialisiert sind (Erling 2018). Aktuell liegen die privat finanzierten Ausgaben für Nachhilfe im schulischen Bereich bei umgerechnet rund 70 Milliarden Euro. Darüber hinaus legt das chinesische Schulwesen weiter großen Wert drauf, dass die Schüler*innen die Lehrenden möglichst gut kopieren. Eigene Weiterentwicklungen der Schüler*innen sind zumindest an den allgemeinbildenden Schulen in China nicht sehr verbreitet.

Außerdem gibt es ein für sich entwickelnde Länder übliches Ungleichgewicht zwischen dem Bildungsstand von Stadt- und Landbewohnern: Während der Bildungsstand in Städten mit dem anderer Länder mithalten kann, brechen offenbar zwei von drei Schulkindern auf dem Land die Schule vor Ende der Schulpflicht ab (derzeit 9 Schuljahre).

Bisher war das geringere Bildungsniveau für die chinesische Wirtschaft nicht unmittelbar von Nachteil, weil der größte Teil der Produktion und die Haupteinnahmen durch Arbeiten als ,verlängerter Werkbank“ für die westliche Welt generiert wurde. Derselbe geringe Bildungsstand wird aber aller Voraussicht nach die Weiterentwicklung des Landes behindern, so der Stanford-Ökonom Rozelle (Ankenbrand, Bildungsproblem in China: Zwei von drei chinesischen Landkindern brechen Schule ab, 2017a). Denn um führend bei Innovationen, KI und in der Wirtschaft zu werden, braucht es viele, selbständig denkende und weiterentwickelnde Geschäftsleute mit einer hochwertigen Ausbildung. 
Allerdings scheint die Qualität der chinesischen Universitäten noch nicht auf einem ähnlich hohen Niveau im Vergleich zu anderen Ländern zu sein. Laut Bertelsmann-Stiftung sind im Times Ranking der 100 weltweit besten Hochschulen 2014-2015 nur zwei chinesische Universitäten zu finden (Bertelsmann-Stiftung 2018, S. 43).

Das ändert aber nichts dran, dass die Anzahl der Studenten an chinesischen Hochschulen jedes Jahr um $16 \%$ steigt. Vielleicht erlaubt China wegen der noch nicht optimalen Qualität der inländischen Hochschulen seinen Talenten außerdem zunehmend, im Ausland zu studieren, wie Abb. 2.10 zeigt. Auch deren Anzahl wächst jährlich um jeweils $14 \%$. Schätzungen gehen davon aus, dass in China zwischen 200 und 300 Millionen Chinesen Englisch lernen. Das ist eine Größenordnung, welche der Bevölkerung der USA entspricht. (Dyer 2014, S. 142). Im Jahr 2030 werden, laut Vorhersagen, $37 \%$ der Wissenschaftler*innen in der Welt aus China kommen, nur 4,2 \% aus den USA und 1,4 \% aus Deutschland (Wolff und Yogeshwar 2019). Selbst wenn man die Bevölkerungszahl dieser Länder zur Gewichtung und damit zum fairen Vergleich heranzieht, bleibt die Tatsache, dass ein Land, das $37 \%$ der Wissenschaftler*innen vereinigt, wahrscheinlich dann mehr und auch bessere Forschung und Patente hervorbringen wird. Das legt schon das Gesetz der Wahrscheinlichkeit nahe. Bereits 2017 lag der chinesische Anteil der weltweiten Patentanmeldungen bei 43,6 \%, während die USA als zweitgrößter Anmelder auf 19,2 \% kam (World Intellecutal Property Organization 2018, S. 7).

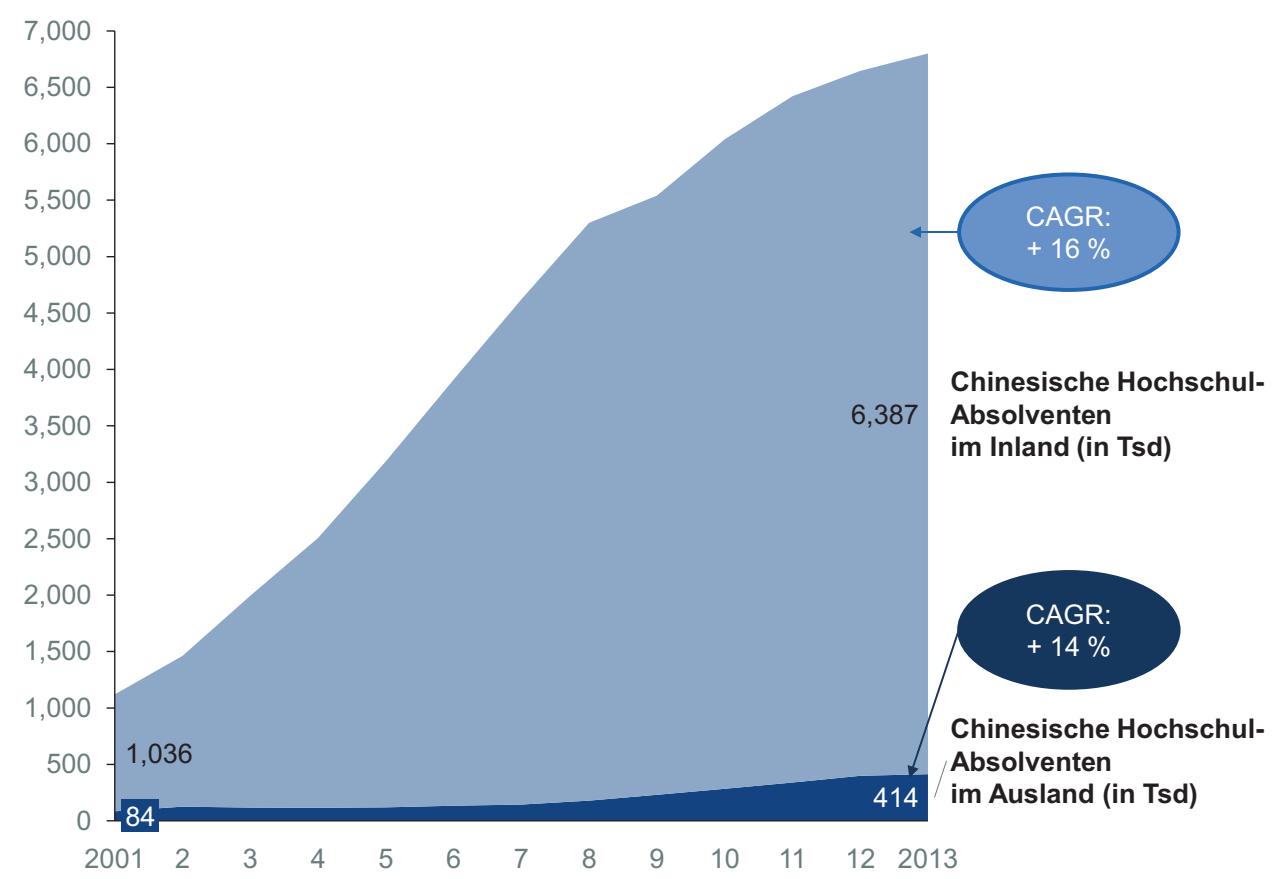

Abb. 2.10 Chinesische Hochschulabsolventen im Inland und Ausland 2001-2013. (Eigene Darstellung nach (National Bureau of Statistics of China 2014a, b). CAGR bezeichnet das durchschnittliche jährliche Wachstum über die angegebene Zeit) 


\section{Gezieltes Anwerben von KI-Talenten weltweit}

Auch dies ist eine explizit in der KI-Strategie der Regierung formulierte Maßnahme: „Improve the AI education system, strengthen the construction of a talent pool and echelons, especially accelerate the introduction of the world's top talent and young talent, forming China's AI top talent base“ (Webster et al. 2017). Mit anderen Worten, es sollen sowohl im Inland die besten Talente gesucht und ausgebildet als auch im Ausland Toptalente angeworben werden.

Durch all diese Aktivitäten ändert sich auch die Art und Weise, in der China am Wirtschaftsgeschehen teilnimmt. Bisher war „Made in China“ zunächst geprägt von „Copy Paste“, gefolgt von „Copy - Optimize“. Dies wandelt sich gerade immer mehr zu „Hack, Combine and Share“ (Kurfiss 2019). Die neue Generation der Startups in China ist in der Lage, eigene, neue Dinge kreativ zu entwickeln und das in einer so disziplinierten Art und Weise, dass die Geschwindigkeit und der Erfolgsdruck der Startup-Szene in China sprichwörtlich wird: „There are only the quick and the dead.“ Diese neue Art des Denkens führt dazu, dass chinesische Firmen ihre Plattformen öffnen, mit anderen kollaborieren und die beste, kreativste, innovativste Idee gewinnen wird. Man könnte es so zusammenfassen: „China kopiert nicht mehr, China erfindet“" (Wolff und Yogeshwar 2019).

Dieses Kapitel hat gezeigt, wie China in diesem „KI-Spiel“ gerade seine Figuren in die richtige Stellung bringt. In einem Satz: China ist auf dem Weg zu einem „AI-first“-Land. Aber wer hat denn nun eigentlich bei KI die Nase vorne? Das zeigt das nächste Kapitel.

\subsection{China: „Der Westen“ - Wer holt die KI-Meisterschaft?}

Das ist natürlich schwer letztgültig zu sagen, denn jeder Blickwinkel auf KI ist ein wenig anders. Ich gehe im Folgenden auf zwei Beispiele ein:

\section{Kai Fu Lee, „AI Superpowers“}

Lee geht von seinem Wissen als KI-Experte und Kenner sowohl der westlichen als auch der chinesischen Welt aus und vergleicht die aktuellen und zukünftigen KI-Fähigkeiten der USA und Chinas, welche beiden Ländern ermöglichen, im Bereich KI weltweit zu führen (Lee 2018, S. 107-136). Dies erläutert er anhand seiner vorher aufgestellten vier Entwicklungswellen von KI (siehe Abschn. 3.4):

Welle 1: Internet-KI: Hier sieht Lee das Verhältnis der Fähigkeit zu führen bei etwa 50:50 zwischen den USA und China. Er sagt vorher, dass in etwas fünf Jahren, also um 2023 herum, China einen leichten Vorteil haben wird und begründet das mit der Tatsache, dass China mehr Internetnutzer*innen hat als die USA und Europa zusammen. Diese Nutzer*innen bezahlen mobil, so dass der Datenfluss bis zum Abschluss eines Kaufs digital geschlossen ist.

Welle 2: Business-KI: Hier haben, Lee zufolge, aktuell die USA die Nase vorne (90:10). Er sagt jedoch voraus, dass China in den nächsten fünf Jahren aufholen wird auf etwa 70:30, wobei 30 die chinesische Seite der Gleichung ist. Die Führungsposition der USA liege, Lee zufolge, daran, dass in der Welt der Business-KI die offline-Daten der Unter- 
nehmen in den USA in der Regel strukturiert zur Verfügung stehen, während sie in China eher unstrukturiert vorliegen.

Welle 3: Perception-KI: Hier liegt aktuell China vorne in einem von Lee geschätzten Verhältnis von 60:40. Er rechnet mit einem wahrscheinlich noch deutlicheren Vorsprung von China vor den USA in 5 Jahren, (80:20), weil chinesische Bürger*innen eher als USAmerikaner*innen bereit sind, auf die persönlichen Schutzrechte ihrer Daten zu verzichten, um einen eigenen Convenience-Vorteil zu erzielen.

Welle 4: Autonome KI: Hier seien, Lee zufolge, US-amerikanische Unternehmen, z. B. bei selbstfahrenden Autos, China zwei bis drei Jahre in der Entwicklung voraus. Das liege an dem Umstand, dass selbstfahrende Autos eine Komplexität darstellt, die nur von Weltklasseteams in KI gelöst werden könnten. Diese Weltklasseteams seien aktuell eher bei Google und Co in Silicon Valley als anderswo auf der Welt zu finden. Die Firmen in den USA hätten viel früher angefangen, selbstfahrende Autos zu entwickeln, Google beispielsweise im Jahr 2009, während China ernsthaft erst 2016 damit begonnen habe. Zusammenfassend sieht Lee die USA bei Autonomer KI gegenwärtig noch in einer Führungsrolle im Verhältnis 90:10. In fünf Jahren geht er eher von 50:50 aus.

Kurzgefasst führt China nach Lees Meinung schon heutzutage eindeutig bei Perception-KI und hat auch bei Internet-KI den Führungplatz inne, allerdings nicht allein. In fünf Jahren, mutmaßt er, wird China bei Internet-KI und bei Perception-KI an erster Stelle stehen und sich bei Autonomer KI den ersten Platz mit den USA teilen.

\section{McKinsey Global Institute, „Notes from the Frontier“}

Das McKinsey Global Institute kombiniert Zahlen und Experteneinschätzung und bewertet mit einer sehr ausführlich beschriebenen Logik die heutige „Readyness“ einzelner Staaten für KI (McKinsey Global Institute 2018, S. 30-34). Dafür gebe es KI-Indikatoren, zu denen gezählt werden: Investitionen in KI, KI-Forschungsaktivitäten und potentieller Produktivitätsanstieg durch KI und Automatisierung. Als sogenannte „KI-Enabler“ werden betrachtet: Digitale Absorber, z. B. Breitbandausbau, Innovationsgrundlagen, Humankapital, z. B. mathematisch-wissenschaftliche Fähigkeiten von Schüler*innen, Austauschfähigkeit des Landes mit anderen Ländern, Arbeitsmarktstruktur und -flexibilität).

McK trennt nach der Analyse die untersuchten Länder in vier Gruppen, abhängig von ihrer „AI-Readyness“ (siehe Abb. 2.11).

In der ersten Gruppe - , aktiv global führende Länder“- befinden sich nach dieser Analyse nur die USA und China, die aktuell auch die Spitzenpositionen einnehmen. Es lohnt sich, die Originalzusammenfassung der McK-Analyse dazu zu zitieren (McKinsey Global Institute 2018, S. 32):

„These two countries are currently leading the race to supply AI, and they have unique strengths that set them apart from all others. Scale effects enable more significant investment, and network effects enable these economies to attract the talent needed to make the most of AI. Together, they are responsible for the vast majority of AI-related research activities. They are a long way ahead of other countries on AI-related patents, publications, and citations. They also make substantial investment in AI. In terms of external investment 
Varying conditions among countries imply different degrees of Al adoption and absorption, and therefore economic impact.

Above threshold ${ }^{1}$ Within threshold ${ }^{1}$

Below threshold 1

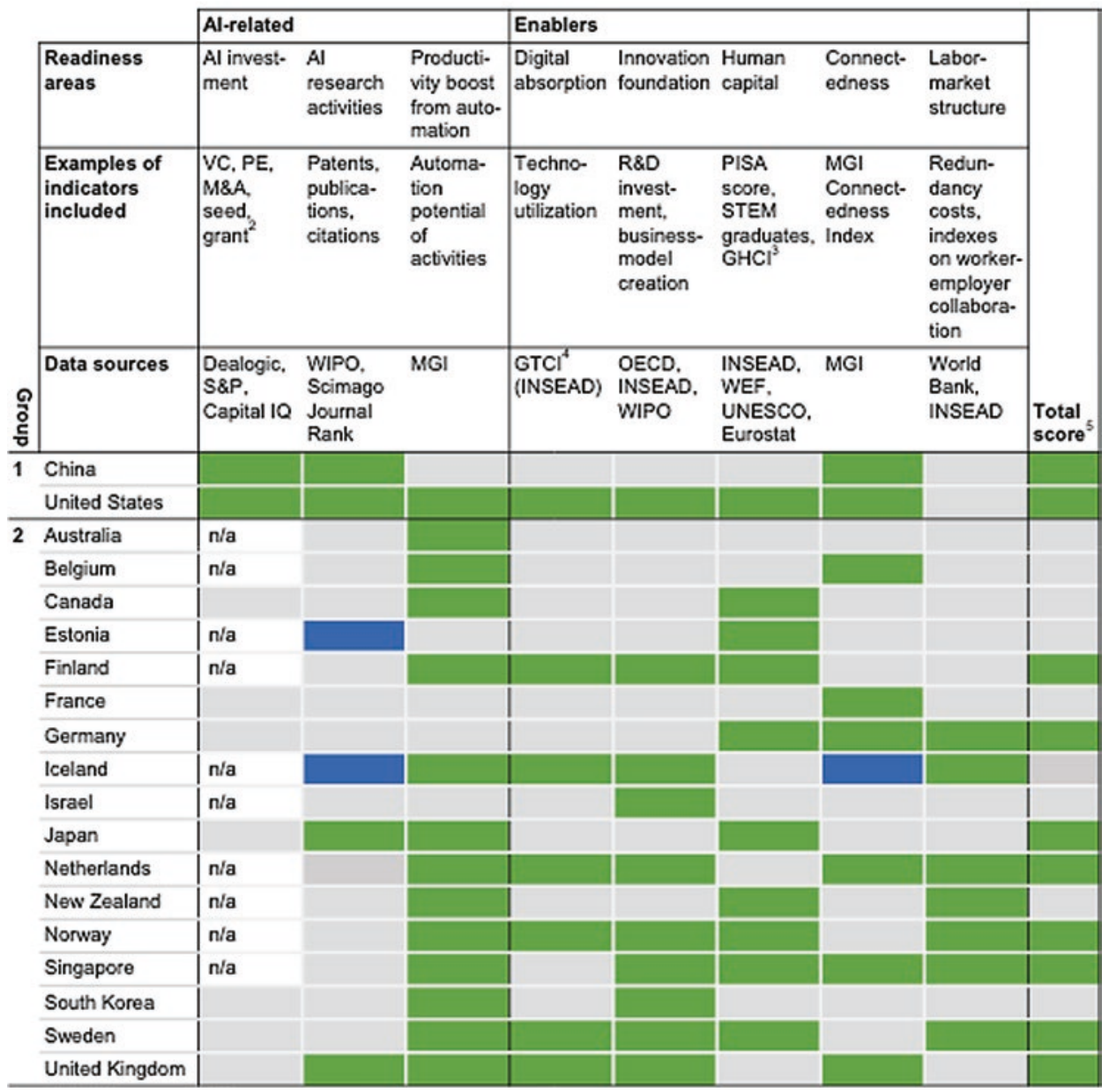

Abb. 2.11 Grad der KI-Aufnahmefähigkeit eines Landes (McKinsey Global Institute 2018, S. 32. Der zweite Teil der Analyse (Landesgruppen 3 und 4) wird hier aus Platzgründen nicht gezeigt. Zu den in der Grafik gezeigten Fußnoten führt McKinsey aus: 1) for the threshold, we calculated a global average and then measured standard deviation. If countries are generally one standard deviation above the average, we categorized them as ,above" and one standard deviation below average as ,,below“; we categorized the rest as being ,within." For certain dimensions where values for leading countries are far higher than the average, we lowered the threshold to show relative differences clearly. 2) VC = venture capital; $\mathrm{PE}=$ private equity; $\mathrm{M} \& \mathrm{~A}=$ mergers and acquisitions. 3) PISA = Programme for International Student Assessment, OECD; STEM = science, technology, engineering, and math; GHCI= Global Human Capital Index; WEF= World Economic Forum. 4) GTCI= Global Talent Competitiveness Index. 5) The score is calculated based on a weighted average of each area that can have a different degree of impact on GDP growth per their elasticity. NOTE: The contents of this table are indicative. Countries in each group are listed in alphabetical order) 
(investment from one firm to another), including venture capital, private equity, and M\&A, the United States accounted for 66 percent, while China was a distant second with 17 percent in 2016. However, China's share is growing rapidly. These countries also have solid enablers. In 2016, they invested about 2 to 3 percent of GDP in overall R\&D. Depending on national priorities and business opportunities, these huge R\&D investment capacities could be channeled into AI. Although China's capacity to innovate is increasing, the economy is digitizing quickly, and investment in AI is substantial. China and the United States are also the large contributors to global trade (in terms of both exports and imports), responsible for more than 20 percent of all the value being traded globally."

McK simuliert dann die KI-Absorption der einzelnen Länder in der Zukunft (nicht ohne darauf hinzuweisen, dass die Ergebnisse der Simulation nur indikativ zu verstehen seien) und sagt voraus, das die aktuelle „KI-Absorptionsfähigkeit“ eines Landes der Treiber für den zukünftigen wirtschaftlichen Erfolg sein wird. In einigen Ländern sei das Wachstum der Wirtschaft durch KI sogar so groß wie die Prognose für das Wachstum des Bruttoinlandsproduktes (siehe Abb. 2.12).

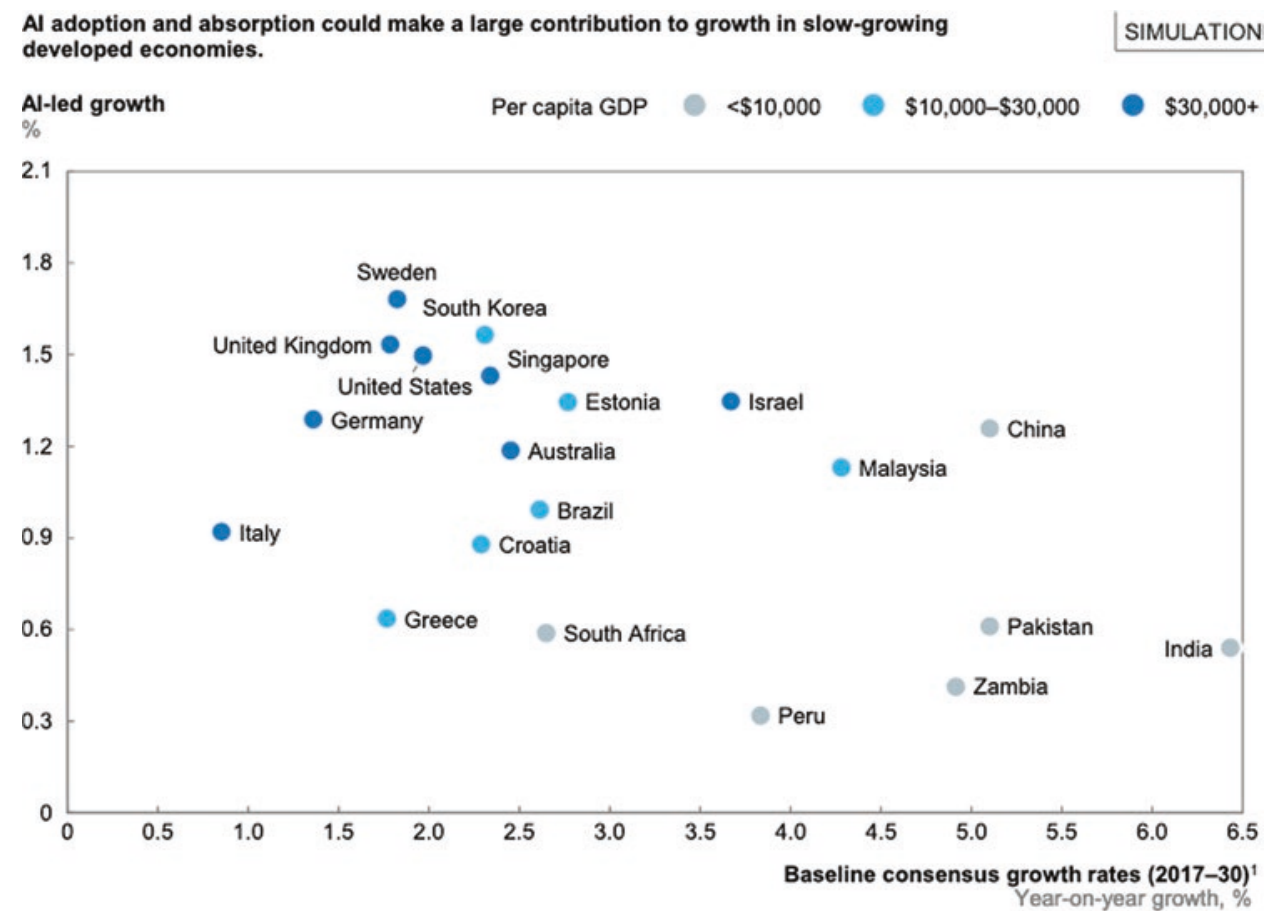

1 Consensus based on IHS Markit, Economist Intelligence Unit, and Oxford Economics. NOTE: Numbers are simulated figures to provide directional perspectives rather than forecasts.

SOURCE: IHS Markit; Economist Intelligence Unit; Oxford Economics; McKinsey Global Institute analysis

Abb. 2.12 Simulation Einfluss von KI auf die Wirtschaft einzelner Länder ((McKinsey Global Institute 2018, S. 36). „Consensus“ ist eine internationale Firma, die Wirtschaftsprognosen erstellt. Gezeigt wird in der Grafik das erwartete Wachstum des Bruttoinlandsproduktes über Zeit) 
Legt man diese Analyse zugrunde, sind die USA und China zur Zeit am besten gerüstet, aus KI das Optimale für ihre Wirtschaft herauszuholen.

Beiden Einschätzungen, der von Lee und der von McK, ist gemeinsam, dass USA und China das Spiel unter sich ausmachen werden. Europa spielt keine Rolle mehr, andere Länder wie beispielsweise Indien noch nicht.

\subsection{Einschätzungen von Matthias Müller, German Centre for Industry and Trade: „China ist in Sachen KI das derzeit größte Testlabor der Welt"}

Matthias Müller lebt seit 1998 in China. Hier verantwortete er zunächst bei der German Industry and Commerce Beijing (GIC) und der German Chamber of Commerce in China (AHK, zuletzt als Head of Marketing, die Marketingaufgabe. Von 2004-2006 betreute er als Director of Marketing/PR das Marketing der TUI China. Seit 2006 leitet er als Managing Director und Head of Marketing \& Sales das German Centre for Industry and Trade in Taicang (Jiangsu Provinz), vor den Toren Shanghais.

Was ist für Sie der größte Unterschied zwischen China und der Westlichen Welt, wenn es um Innovationen und Marketing geht?

China hat in den letzten zwei Dekaden den Aufstieg zur zweitgrößten Volkswirtschaft sowie zum größten Absatzmarkt der Welt (für so ziemlich alle Produkte) vollzogen. Seitdem haben nicht nur etliche ausländische Unternehmen ihre F\&E auf dem chinesischen Markt platziert, sondern China selbst hat mit viel Geld und Aufwand die F\&E-Aktivitäten der heimischen Unternehmen gezielt gefördert. Das heißt, nicht nur, dass China eine Vielzahl an Patentanmeldungen zu verzeichnen hat, sondern auch, dass die lokalen Unternehmen immer besser und wettbewerbsfähiger werden. Heute konkurrieren die deutschen Firmen in China zunehmend mit chinesischen Unternehmen.

In Bezug auf Marketing muss auch hier gesagt sein, dass China der zweitgrößte (und wahrscheinlich sehr bald der größte) Werbemarkt der Welt ist. Es sind einfach die unglaublichen Dimensionen, die den Unterschied zu den einzelnen westlichen Ländern ausmachen.

Was würden Sie sagen: Ist China bei KI im Marketing vor oder hinter Europa? Wie viele Jahre?

China ist bei KI weltweit gemeinsam mit den USA führend und Europa gefühlt 5-10 Jahre voraus.

Was wäre aus Ihrer Sicht die größte Veränderung, die Marketing- und Salesmanager*innen in Europa in den nächsten 5 Jahren erfahren werden?

Ich würde das nicht nur auf den Marketing- und Sales-Bereich runterbrechen, sondern auf die europäische Wirtschaft insgesamt. Fakt ist, dass sich gerade global die Kräfteverhältnisse komplett verschieben. Die asiatische Region, und allen voran China ist im Kommen und wird wirtschaftlich in Zukunft eine bzw. die führende Rolle einnehmen. Das ist für viele Manager*innen aus den westlichen Industrienationen immer noch sehr gewöhnungsbedürftig. Aber diese Veränderungen finden statt. Von daher kann ich nur empfehlen, 
sich damit abzufinden bzw. diese Realitäten zu akzeptieren, um künftig entsprechend agieren/reagieren zu können und sich eine gute (Ausgangs-)Position in diesem neuen Umfeld zu schaffen.

Sie erleben seit 20 Jahren die positive wirtschaftliche Entwicklung in China mit. Hätten Sie ein paar Beispiele aus Ihrem Alltag, die diese Entwicklung zeigen?

Das ist wirklich nicht einfach. Was ich in meinen über 20 Jahren in China an Veränderung miterlebt habe, ist für mich auch heute noch einfach unglaublich. Es gibt unzählige Beispiele. Ich denke aber, dass man insbesondere den Aufbau der chinaweiten Infrastruktur hervorheben muss. Die chinesische Regierung hat das komplette Land vernetzt, man kommt wirklich schnell und bequem von A nach B - und das bedeutet in China im Zweifelsfall eine Entfernung von mehreren tausend Kilometern. Als Student bin ich in China noch von Shanghai nach Peking mit dem Zug rund 15 Stunden gefahren. Heute fährt der schnellste Zug die Strecke in rund 4 Stunden und kommt auf die Minute (!!) genau an. Alles wird runderneuert, Autobahnen, Flughäfen, etc., und alles i. d. R. ,state of the art“" Als ich 1998 nach dem Studium in Peking gelandet bin, gab es einen Flughafen (heutiges Terminal 1). Dann kam Terminal 2, Terminal 3 (größtes Terminal der Welt) und gerade ist der neue Flughafen in Daxing (bei Peking) in Betrieb genommen worden.

Ein weiteres Beispiel ist sicherlich auch das Dienstleistungsangebot, welches insbesondere in den letzten 10 Jahren aufgrund der Digitalisierung nicht umfassender sein könnte. Alles, was das Leben und den Alltag einfacher und effizienter macht, gibt es i. d. R. per App. Alleine mit WeChat kann ich überall zahlen, Flüge buchen, Steuern und Strafzettel bezahlen, Taxis rufen, Essen bestellen, Stromrechnung begleichen, Kinotickets buchen, und, und, und.

China arbeitet mit 5-Jahresplänen. Können Sie kurz erklären, was im aktuellen 5-Jahresplan steht und was mit „Made in China 2025 “ gemeint ist? Was ist der „Chinesischen Traum"?

Beim aktuellen 5-Jahresplan geht es im Wesentlichen um die Transformation der Wirtschaft, der Umwelt bzw. den Umweltschutz und vor allem auch gesellschaftliche Themen. Daran kann man sehr gut ablesen, wie sich Chinas Interessen und Prioritäten seit Ende der 70er-Jahre von Deng Xiaoping eingeleiteten Öffnungspolitik verändert haben. Heute geht es um ein kontrolliertes wirtschaftliches Wachstums, die gezielte Förderung von Innovationen und Hi-Tech. „Made in China 2025“ ist das erklärte Langzeitziel Chinas, die weltweite Technolgieführerschaft zu erreichen - insbesondere in den Bereichen Digitalisierung, Robotertechnik und Automatisierung. Vor allem aber hat China seine Umweltprobleme erkannt und geht diese gezielt an, z. B. weg von der Kohle hin zu alternativen Energien. Aus meiner Sicht allerdings sind die gesellschaftlichen Themen die spannendsten. Wenn man sich überlegt, in welcher Geschwindigkeit China sich komplett gewandelt hat ... das geht an einer Gesellschaft nicht spurlos vorbei. Nicht umsonst heißen die aktuellen Schlagworte und Ziele im 5-Jahresplan ,harmonische Gesellschaft“, ,,soziale Stabilität“ usw.

Der „Chinese Dream“ unterscheidet sich eigentlich nicht so sehr vom „American Dream“. Prinzipiell ermöglichen die politischen Rahmenbedingungen den Chines*innen 
alle Freiheiten, Karriere zu machen und es zu materiellem Reichtum zu bringen bzw. den Lebensstandard zu verbessern. Aber anders als in den USA geht es nicht so sehr um das Individuum, sondern um die Verwirklichung des „Chinese Dream“ aus dem chinesischen Kollektiv heraus, mit einer starken Nation und der kommunistischen Partei im Rücken.

Welche Rolle spielt bei diesem Langzeitziel aus Ihrer Sicht KI und Big Data?

Eine sehr große Rolle. KI und Big Data sind die wesentlichen Grundvoraussetzungen, um „Made in China 2025“ und den Chinesischen Traum zu realisieren. Kein anderes Land verfügt über so einen großen Datenbestand wie China bzw. kann darauf zurückgreifen. Derzeit ist China in Sachen KI das größte Testlabor der Welt. Zudem hat die chinesische Regierung größtes Interesse an der Digitalisierung, um die Gesellschaft zu überwachen und deren Sicherheit zu gewährleisten. Ob es nun um Verkehrsüberwachung, Strafverfolgung oder andere Bereiche geht, es kommt überall zum Tragen. Bei der Gesichts- und Spracherkennung liegt China mittlerweile bei $100 \%$.

Wir sprechen in Deutschland sehr viel darüber, dass unsere Verwaltung eher langsam arbeitet. Sie haben viel mit Behörden in China zu tun. Sehen Sie Unterschiede, z. B. in der Geschwindigkeit? Wenn ja, welche?

Generell bereitet bürokratischer Aufwand nirgendwo in der Welt viel Freude. Aber ich kann deutlich erkennen, dass China sich auch hier ständig weiterentwickelt und mittlerweile sehr, sehr viel digital bzw. online abgewickelt werden kann. Die Ämter werden immer moderner und kundenfreundlicher gestaltet. Und auch wenn eine Behörde voller Menschen ist, läuft die Abwicklung doch sehr zügig und organisiert. Und dass auf meinem Steuerbescheid „Thank you for contributing to China's prosperity“ steht, ist einfach eine nette Geste, über die ich immer noch schmunzeln muss.

Welche Erfolge hat China bereits zu verzeichnen?

China wird in den deutschen Medien sehr oft hart angegangen. Das ist aus meiner Sicht nicht immer fair und hängt zu allererst davon ab, aus welcher Perspektive man beurteilt. Viele Stimmen westlicher Industrienationen fordern von China z. B. Demokratie. Ein Mitspieler aus meiner Fußballmannschaft hier in China, der aus einem kleinen armen afrikanischen Land kommt, sieht zuerst, dass China es geschafft hat, die Grundbedürfnisse von 1,4 Milliarden Menschen zu befriedigen, oder anders ausgedrückt, seine Bevölkerung „durchzufüttern“. China hat seit Anfang der 80er-Jahre über 700 Mio. Chinesen aus der Armut geführt. China exportiert weder Terrorismus noch Wirtschaftsflüchtlinge. Und die umfassende Modernisierung der Infrastruktur, die stete Erhöhung des Wohlstands, der Ausbau des Sozialversicherungssystems und die Stärkung der Arbeitnehmerrechte sind weitere Errungenschaften. Auch mit der gewachsenen internationalen Verantwortung geht China meines Erachtens gut um, ist eine gemäßigte Stimme im UN-Sicherheitsrat und stellt u. a. ein der größten Blauhelm-Kontingente.

Wenn Sie Marketingmanager*innen in Europa einen Tipp geben sollten, was sie mehr/ besser machen sollten, um wettbewerbsfähig zu sein, was wäre das?

Na ja ... die Marketingmanager*innen können ja letztendlich auch nur vermarkten, was die europäischen Firmen an Produkten zu bieten haben. Ich denke vielmehr, dass Europa 
aufpassen muss, nicht den Anschluss zu verlieren, insbesondere bei der Digitalisierung und bei Innovationen. Wenn Europa aus gemeinsamer Stärke heraus agiert und international mit einer Stimme spricht, werden die Firmen auch wettbewerbsfähig bleiben. Unabhängig davon sollte man immer ein Auge auf die Entwicklung und Fortschritte im asiatischen Raum und vor allem in China haben. Beispielsweise macht uns China gerade bei der 5G-Technologie vor, wie es geht.

\subsection{Fazit: Darum wird der Sack Reis, der in China umfällt, wichtig für uns}

Die chinesische und die westlich geprägte Welt unterscheiden sich deutlich voneinander. Während der Westen von Demokratie, Datenschutz und den wirtschaftlichen Erfolgen der industriellen Revolution zehrt, stellt China gerade die Weichen, um die führende globale Macht des 21. Jahrhunderts zu werden. China hat drei sogenannte 5-Jahrespläne, die diesen Anspruch in die Tat umsetzen sollen: Einen Plan zur Optimierung der Industrie bis 2025, einen Plan, China zur führenden globalen Macht bis 2050 aufzubauen und einen, der KI priorisiert, weil man diese Technologie als Treiber für die beiden anderen Ziele ansieht. Für alle Staaten der westlichen Welt ist augenfällig, dass China in einer schnellen wirtschaftlichen Entwicklung begriffen ist. Und vielleicht können wir noch nicht in seiner Gänze nachvollziehen, mit welcher Entschlossenheit diese Entwicklung vorangetrieben wird und welche Schwerpunkte Hand in Hand mit Gesellschaft, Führung und Wirtschaft gesetzt werden.

Das kollektive kulturelle Erbe macht es für die Menschen in China leichter als für jene in westlichen Gesellschaften, mit neuen Technologien kollektiv umzugehen. Der geringe Personendatenschutz und die Tatsache, dass China das bevölkerungsreichste Land der Erde ist, spült deutlich mehr Daten zum Analysieren in die KI-Systeme, als dies im Westen derzeit möglich ist. Der strengere chinesische Landesdatenschutz bringt es außerdem mit sich, dass einerseits die eigenen Daten im Lande bleiben und andererseits der Knowledgetransfer nach China hinein besser funktioniert als aus China heraus. Die Regierung unterstützt darüber hinaus mit viel Geld die Ausbildung von KI-Expert*innen im In- und Ausland, die Optimierung des Schul- und Ausbildungsssystems auch in Bezug auf KI-Fähigkeiten und erleichtert bürokratische Vorgänge rund um KI.

Es kommen in China also die drei Faktoren zusammen, die es braucht, um auf dem Sektor der KI führend zu werden: KI-Technologie und Fachpersonal, große Mengen miteinander verknüpfter Daten und ein genügend hohes Budget, um daraus Neues zu entwickeln. Kein Wunder, dass die „Big Three“, also Baidu, Alibaba und Tencent den Vergleich mit den „Big Four“ der westlichen Welt, Google, Apple, Facebook und Amazon, nicht scheuen müssen. Hier werden die nächsten KI-Innovationen entstehen, hier werden wir hinschauen müssen, um lernen zu können. Es wird für uns im Westen wichtig werden, ob und wie der sprichwörtliche Sack Reis in China umfällt. Wo wir tatsächlich heute schon im Bereich Marketing von China lernen können, zeigen die nächsten Kapitel. 


\section{Management Summary}

\section{China wird vom sogenannten Westen unterschätzt}

- China war 2000 Jahre lang die führende Wirtschaftsmacht der Welt, lediglich in den letzten 200 Jahren spielte China eine weniger bedeutende Rolle. Das ändert sich gerade. Seit etwa 1980 wachsen das Pro-Kopf-Einkommen und die Wirtschaft, parallel sinkt die Armut. Zeitlich verzögert, aber ebenfalls deutlich sichtbar, vollzieht Indien eine ähnlich steile Wachstumskurve.

\section{Dabei wird China gerade bei KI vermutlich weltweit führend werden - Das hat vier Gründe}

- China will führen, nicht nur in der Wirtschaft, sondern auch in der Gesellschaft. Davon zeugen die aktuellen 5-Jahrespläne des planwirtschaftlich geführten Landes. Das Ziel ist die Weltführerschaft bis 2049, dem 100. Geburtstag der Kommunistischen Partei in China. Ein extra Plan identifiziert KI dabei als wichtigen Treiber und fördert diesen Treiber mit klar definierten KI-Zielen, Geld und mit der Unterstützung durch die Behörden.

- China tut alles, damit sein Ziel der Weltführerschaft erreicht werden kann. Es steckt deutlich mehr Geld in die KI-Entwicklung als viele westliche Staaten, unterstützt die KI-Bildung, kauft weltweit Expert*innen ein und sorgt dafür, dass die Behörden darauf ausgerichtet sind, schnell und unbürokratisch Unterstützung $\mathrm{zu}$ leisten.

- China hat rund 1,4 Milliarden Menschen, die finanziell nach und nach in den Mittelstand wachsen und nun das Geld haben, sich Smartphones anzuschaffen. So entsteht auf der einen Seite ein großer Handelsmarkt im eigenen Land, auf der anderen Seite können Unmengen von Daten gesammelt und analysiert werden.

- China hat ein anderes Verständnis von Datenschutz als der sogenannte Westen. Aus diesem Grunde können über KI Daten einzelner Personen umfassender analysiert werden. Wer die meisten verknüpften Daten besitzt und diese am besten und schnellsten analysieren kann, hat aller Voraussicht nach den optimalen Schlüssel zum wirtschaftlichen Erfolg.

Im aktuellen KI-Wettlauf steht es gerade 1:1 zwischen den USA und China, Europa, UK und Deutschland spielen eine nur untergeordnete Rolle 


\section{Literatur}

Alsabah, N. (31. März 2017). Peking will gläserne Unternehmen.https://www.zeit.de/politik/ausland/2017-03/netzpolitik-china-cybersicherheit-zensur-internet. Zugegriffen am 29.07.2019.

Ankenbrand, H. (21. September 2017a). Bildungsproblem in China: Zwei von drei chinesischen Landkindern brechen Schule ab.https://www.faz.net/aktuell/wirtschaft/agenda/bildungswesen-in-china-63-prozent-der-kinder-brechen-schule-ab-15209056.html. Zugegriffen am 26.07.2019.

Ankenbrand, H. (17. Oktober 2017b). China will 2019 weltgrößten Flughafen eröffnen. https:// www.faz.net/aktuell/wirtschaft/agenda/china-will-2019-weltgroessten-flughafen-eroeffnen-15250177.html. Zugegriffen am 31.07.2019.

Benrath, B., \& Bartsch, B. (30. November 2018). Asien in Zahlen - Teil II - Punktabzug für zu seltene Besuche bei den Eltern. https://www.faz.net/aktuell/wirtschaft/infografik-chinas-sozialkredit-system-15913709.html. Zugegriffen am 30.07.2019.

Benrath, B., Bartsch, B., Giesel, J., \& Helfert, B. (12. Dezember 2018). Asien in Zahlen - Teil 3 - Made in China 2025. https://www.faz.net/aktuell/wirtschaft/infografik-made-in-china-2025-15936600. html. Zugegriffen am 29.07.2019.

Bertelsmann-Stiftung. (2006-2018). BTI 2018 transformationsindex.https://www.bti-project.org/ de/daten/. Zugegriffen am 16.07.2019.

Bertelsmann-Stiftung. (2018). The race for AI supremacy. https://www.bertelsmann-stiftung.de/de/ unsere-projekte/deutschland-und-asien/projektthemen/asia-in-infographics/. Zugegriffen am 05.10.2019.

Dabringhaus, S. (2011). Mitte der Welt. Zeit Geschichte, 1, 84.

Dorloff, A. (24. März 2019). Auf dem Weg zur totalen Überwachung. 29. Juli 2019 von https://www. tagesschau.de/ausland/ueberwachung-china-101.html

Dyer, G. (2014). The new era of competition with China. London: Penguin.

Erling, J. (18. September 2018). Drillen bis zum Umfallen. https://www.welt.de/politik/ausland/article181543616/Schule-in-China-Peking-will-Nachhilfe-Boom-stoppen.html. Zugegriffen am 26.07.2019.

FAZ. (2018). Macron setzt auf Künstliche Intelligenz. http://www.faz.net/aktuell/wirtschaft/kuenstliche-intelligenz/emmanuel-macron-setzt-auf-kuenstliche-intelligenz-15514715.html. Zugegriffen am 29.05.2018.

Fung Business Intelligence. (Oktober 2018). Spotlight on China retail.http://www.iberchina.org/ files/2019/china_retail.pdf. Zugegriffen am 25.02.2020.

Gapminder. (03. Oktober 2019). Income per person. https://www.gapminder.org/tools/\#\$state\$time $\$$ value $=2040 \&$ startOrigin $=1800 \&$ endOrigin $=2040 \&$ showForecast :true \&delay $: 100 ; \&$ \& ities $\$$ show $\$$ country $\$ /$ in $@=u s a \&=$ chn $\&=$ deu $\&=$ ind $; ; ; ;$ marker $\$$ axis_x $\$$ zoomedMax=2040;;;\&chart-type=linechart. Zugegriffen am 03.10.2019.

Gottschalk, G. (2011). Der Wahn des Tyrannen. Geo Epoche, 51, 111.

Hackhausen, J. (01. Oktober 2012). Wie China den Dollar knacken will. https://www.handelsblatt. $\mathrm{com} /$ finanzen/maerkte/devisen-rohstoffe/neue-weltordnung-china-hat-die-usa-in-derhand/7202126-2.html?ticket=ST-2968219-FagM14NfSoGXRO7KG9nq-ap5. Zugegriffen am 30.07.2019.

Hartl, R. (03. Juli 2019). Flughafen Berlin (BER) Kosten. 31. Juli 2019 von https://www.flughafen-berlin-kosten.de/

Heide, D. (2018). Bundesregierung will Milliarden in KI investieren und den USA und China zuvorkommen. https://www.handelsblatt.com/politik/deutschland/digitalisierung-bundesregierung-will-milliarden-in-ki-investieren-und-den-usa-und-china-zuvorkommen/23626960.html. Zugegriffen am 13.11.2018. 
Hua, S., \& Jahn, T. (2018). Wie China bei der Künstlichen Intelligenz zur Supermacht aufsteigt. https://www.handelsblatt.com/technik/thespark/technik-der-zukunft-wie-china-bei-der-kuenstlichen-intelligenz-zur-supermacht-aufsteigt/23225468.html. Zugegriffen am 25.08.2018.

Ingenieur.de. (01. Juli 2019). Pekings Giga-Flughafen Beijing Daxing Airport ist fertiggestellt. https://www.ingenieur.de/technik/fachbereiche/verkehr/pekings-giga-flughafen-stellt-alles-inden-schatten/. Zugegriffen am 31.07.2019.

International Monetary Fund. (April 2018). World economic and financial surveys. https://www.imf. org/external/pubs/ft/weo/2018/01/weodata/index.aspx. Zugegriffen am 08.07.2019.

International Monetary Fund. (April 2019). Die 20 Länder mit der größten Bevölkerung im Jahr 2018 (in Millionen Einwohner). Statista - Das Statistik-Portal. https://de.statista.com/statistik/ daten/studie/1722/umfrage/bevoelkerungsreichste-laender-der-welt/. Zugegriffen am 02.07.2019.

John, N. (2018). ec.europa. https://ec.europa.eu/germany/news/20181207-kuenstliche-intelligenz de. Zugegriffen am 07.12.2018.

Kurfiss, S. (01. August 2019). Creativity is China's greatest future resource. 11. September 2019 von https://homeofcreativebusinessleadership.com/news/207223. Zugegriffen am 11.09.2019.

Lee, K.-F. (2018). AI superpowers: China, silicon valley, and the new world order. Boston: Houghton Mifflin Hartcourt Publishing Company.

Lepault, S., \& Franklin, R. (2018). China - Die Welt des Xi Jinping. https://www.youtube.com/ watch?v=ABbacXcp80I. Zugegriffen am 07.08.2019.

Lohse, E. (25. Mai 2018). Merkel in China: Wo die Kameras alles sehen. https://www.faz.net/aktuell/politik/ausland/china-kameraueberwachung-bei-merkels-besuch-in-shenzhen-15607878. html. Zugegriffen am 31.07.2019.

Manager Magazin. (10. Januar 2018). China weist Schuldenkönig Trump in die Schranken. https:// www.manager-magazin.de/politik/weltwirtschaft/china-fuehrung-in-peking-weist-trump-in-dieschranken-dollar-faellt-a-1187151.html. Zugegriffen am 25.02.2020.

Manuel, A. (Mai 2019). How to win the technology race with China. https://www.ted.com/talks/ anja_manuel_how_to_win_the_technology_race_with_china. Zugegriffen am 15.07.2019.

McKinsey Global Institute. (September 2018). Notes for the frontier: Modeling the impact of AI on the world's economy. https://www.mckinsey.de/ /media/McKinsey/Locations/Europe\%20 and\%20Middle\%20East/Deutschland/News/Presse/2018/2018-09-05\%20-\%20MGI\%20 AI-Studie\%20Dampfmaschine/MGI-Studie_Notes_from_the_Frontier_2018.ashx. Zugegriffen am 01.08.2019.

National Bureau of Statistics of China. (01. Oktober 2014a). Anzahl der Absolventen allgemeiner Hochschulen in China in den Jahren 2001 bis 2013 (in 1000). https://de.statista.com/statistik/ daten/studie/225949/umfrage/anzahl-der-absolventen-allgemeiner-hochschulen-in-china/. Zugegriffen am 16.07.2019.

National Bureau of Statistics of China. (01. Oktober 2014b). Anzahl der Studenten aus China, die im Ausland studieren in den Jahren 2001 bis 2013 (in 1000). https://de.statista.com/statistik/daten/ studie/225965/umfrage/anzahl-der-chinesischen-studenten-die-im-ausland-studieren/. Zugegriffen am 16.07.2019.

Neuerer, D. (2018). Deutsch-Französische Kooperation - China investiert massiv in Künstliche Intelligenz. https://www.handelsblatt.com/politik/deutschland/deutsch-franzoesische-kooperation-china-investiert-massiv-in-kuenstliche-intelligenz/20982190-2.html. Zugegriffen am 20.02.2020.

OECD. (06. Dezember 2016). PISA 2015 results (Bd. I). http://www.oecd.org/education/pisa-2015results-volume-i-9789264266490-en.htm. Zugegriffen am 15.07.2019.

OECD. (Dezember 2018). Private equity investment in artificial intelligence. http://www.oecd.org/ going-digital/ai/private-equity-investment-in-artificial-intelligence.pdf. Zugegriffen am 15.07.2019. 
Orth, S. (23. März 2019). Couchsurfing in China: Urlaub im Überwachungsstaat. https://www. spiegel.de/reise/fernweh/couchsurfing-in-china-urlaub-im-ueberwachungsstaat-a-1258657. html. Zugegriffen am 31.07.2019.

pwc. (Februar 2017). The world in 2050 - The long view: How will the global economic order change by 2050?https://www.pwc.com/gx/en/issues/economy/the-world-in-2050.html. Zugegriffen am 08.07.2019.

Rosling, H. (2019). Factfullness: Wie wir lernen, die Welt so zu sehen, wie sie wirklich ist. Berlin: Ullstein.

Ryssel, J. M. (05. März 2019). Sozialpunktesystem in China: Eine Welt ohne Datenschutz?https:// www.datenschutzbeauftragter-info.de/sozialpunktesystem-in-china-eine-welt-ohne-datenschutz/. Zugegriffen am 30.07.2019.

Shi-Kupfer, K., \& Chen, G. (20. August 2017). Massenhaft Nutzer - mangelhafter Datenschutz. https://www.zeit.de/politik/ausland/2017-08/china-datenschutz-digitalisierung-gesetze. Zugegriffen am 26.06.2020.

Staatsrat der Volksrepublik China. (07. Juli 2015). Made in China 2025.http://www.cittadellascienza.it/cina/wp-content/uploads/2017/02/IoT-ONE-Made-in-China-2025.pdf. Zugegriffen am 16.07.2019.

Steinmetz, V. (21. Juli 2017). Was China in Dschibuti vorhat. https://www.spiegel.de/politik/ausland/china-eroeffnet-militaerbasis-in-dschibuti-welche-ziele-verfolgt-peking-a-1158755.html. Zugegriffen am 07.08.2019.

Stern. (27. März 2019). Bau von BER-Flughafen: Erinnern Sie sich an diese Nachricht? Sie ist 20 Jahre alt - aber erschreckend aktuell. https://www.stern.de/reise/deutschland/ber-flughafen\%2D\%2Dso-wurde-vor-20-jahren-ueber-den-baubeginn-berichtet-8641102.html. Zugegriffen am 31.07.2019.

Trivium China. (23. September 2019). Understanding China's social credit system.http://socialcredit.triviumchina.com/wp-content/uploads/2019/09/Understanding-Chinas-Social-Credit-System-Trivium-China-20190923.pdf. Zugegriffen am 24.02.2020.

UN. (2019). World population prospects 2019. United Nations. https://population.un.org/wpp/ Graphs/Probabilistic/POP/TOT/356. Zugegriffen am 02.07.2019.

Webster, G., Creemers, R., Triolo, P., \& Kani, E. (01. August 2017). Full translation: China's ,new generation artificial intelligence development plan ' (2017). https://www.newamerica.org/cybersecurity-initiative/digichina/blog/full-translation-chinas-new-generation-artificial-intelligence-development-plan-2017/. Zugegriffen am 16.07.2019.

Wikipedia. (15. März 2019a). Digital ecosystem. https://en.wikipedia.org/wiki/Digital_ecosystem. Zugegriffen am 06.07.2019.

Wikipedia. (24. Juli 2019b). Shenzhen. https://de.wikipedia.org/wiki/Shenzhen\#Die_Zeit_vor_der_ Gr\%C3\%BCndung_der_Sonderwirtschaftszone. Zugegriffen am 31.07.2019.

Wolff, T., \& Yogeshwar, R. (20. August 2019). Der große Umbruch - Wie Künstliche Intelligenz, unser Leben verändert. https://www1.wdr.de/mediathek/video/sendungen/video-der-grosse-umbruch\%2D\%2Dwie-kuenstliche-intelligenz-unser-leben-veraendert-100.html. Zugegriffen am 01.09.2019.

World Intellecutal Property Organization. (2018). World intellectual property indicators 2018. 04. September 2019 von https://www.wipo.int/edocs/pubdocs/en/wipo_pub_941_2018.pdf. Zugegriffen am 04.09.2019.

Wurzel, S. (03. März 2019). Reiseverbot für Millionen Menschen. https://www.tagesschau.de/ausland/sozialkredit-ranking-china-101.html. Zugegriffen am 30.07.2019.

$\mathrm{Xi}$, J. (18. Oktober 2017). Secure a decisive victory in building a moderately prosperous society in all respects and strive for the great success of socialism with Chinese characteristics for a new era.http://www.xinhuanet.com/english/download/Xi_Jinping's_report_at_19th_CPC_National_ Congress.pdf. Zugegriffen am 16.07.2019. 